Review

\title{
Molecular Imaging of Apoptosis: From Micro to Macro
}

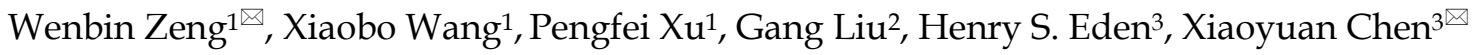 \\ 1. School of Pharmaceutical Sciences, and Molecular Imaging Research Centre, Central South University, Changsha, 410013, China; \\ 2. Centre for Molecular Imaging and Translational Medicine, State Key Laboratory of Molecular Vaccinology and Molecular Diagnostics, \\ School of Public Health, Xiamen University, Xiamen, 361102, China. \\ 3. Laboratory of Molecular Imaging and Nanomedicine, National Institute of Biomedical Imaging and Bioengineering, National Institutes \\ of Health, Bethesda, Maryland, 20892, USA.
}

$\square$ Corresponding author: wbzeng@hotmail.com (W.Z.); shawn.chen@nih.gov (X.C.).

(c) 2015 Ivyspring International Publisher. Reproduction is permitted for personal, noncommercial use, provided that the article is in whole, unmodified, and properly cited. See http://ivyspring.com/terms for terms and conditions.

Received: 2015.01.09; Accepted: 2015.02.18; Published: 2015.02.20

\begin{abstract}
Apoptosis, or programmed cell death, is involved in numerous human conditions including neurodegenerative diseases, ischemic damage, autoimmune disorders and many types of cancer, and is often confused with other types of cell death. Therefore strategies that enable visualized detection of apoptosis would be of enormous benefit in the clinic for diagnosis, patient management, and development of new therapies. In recent years, improved understanding of the apoptotic machinery and progress in imaging modalities have provided opportunities for researchers to formulate microscopic and macroscopic imaging strategies based on well-defined molecular markers and/or physiological features. Correspondingly, a large collection of apoptosis imaging probes and approaches have been documented in preclinical and clinical studies. In this review, we mainly discuss microscopic imaging assays and macroscopic imaging probes, ranging in complexity from simple attachments of reporter moieties to proteins that interact with apoptotic biomarkers, to rationally designed probes that target biochemical changes. Their clinical translation will also be our focus.
\end{abstract}

Key words: Apoptosis, Microscopic imaging assays, Macroscopic imaging probes, Clinical translation.

\section{Introduction}

\section{There is no life without death. - Dogen Zenji}

Multicellular organisms have evolved a mechanism of programmed cell death termed "apoptosis" more than 40 years ago by Kerr et al. [1] to eliminate redundant cells during the course of embryonic development, normal maintenance of homeostasis, and under pathological circumstances. However, dysregulation of apoptosis can lead to the destruction of normal tissues, resulting in a variety of disorders, including autoimmune and neurodegenerative diseases (if there's too much apoptosis) or the growth of tumors (if there's too little) [2,3]. In particular, successful tumor treatments, such as radiation, chemotherapy, thermal therapy and photodynamic therapy, iatrogenically induced apoptosis [4-6]. Given the cen- tral role of apoptosis, it would be desirable to have a robust imaging method to detect and monitor this process.

Studies of specific biochemical changes in cells undergoing apoptosis have identified three main apoptotic pathways, including the: i) mitochondrial (or intrinsic) pathway, mediated by the Bcl-2 superfamily members that interact with the mitochondrial membrane; ii) death receptor (extrinsic) pathway, governed by specific death receptors that bind specific ligands, including tumor necrosis factor (TNF),TRAIL (a TNF-related, apoptosis-inducing ligand that binds to the DR4 and DR5 death receptors), and FasL (a ligand that binds to the Fas receptor); and iii) endoplasmic reticulum stress pathway, mainly regulated 
by IRE1- and CHOP-mediated proapoptotic signaling [7-10]. At the heart of each pathway is the activation of caspases, cysteine aspartate-specific proteases--which exist as inactive zymogens under normal conditions. All the pathways ultimately converge on the executive enzyme caspase- 3 . The activation of caspase- 3 results in the activation of poly-ADP-ribose polymerase (PARP), an enzyme that facilitates the degradation of nuclear DNA into 50- to 300-kilobase-sized pieces (DNA ladder formation), along with the morphologic events of apoptosis [11]. One of the earliest biochemical events occurring during the apoptotic process is the externalization of phosphatidylserine (PS) [12]. Following PS externalization, cytoplasm shrinkage occurs, therewith cell shrinkage, membrane blebbing, and fragmentation of the cell into apoptotic bodies. The net result of apoptosis is the orderly breakdown of a cell via compression, and self-packaging of cellular proteins. Of note, due to their similar characteristics in morphology and molecular biology and intricate cross-talks $[13,14]$, apoptosis is often confused with other types of cell death including autophagy and programmed necrosis. The methods for distinguishing apoptosis from other types of programmed cell death would be valuable.

Over the past two decades, various microscopic and macroscopic imaging modalities have been developed to detect apoptosis. Microscopic methods require harvesting tissue invasively and imaging by cell-based assays. By contrast, macroscopic imaging modalities, which have become common following the emergence of molecular imaging in the late 1990s [15], visualize apoptosis in living subjects noninvasively. To date, various molecular imaging technologies have been employed to study apoptosis in vivo, including single photon emission computed tomography (SPECT), positron emission tomography (PET), magnetic resonance imaging (MRI), optical imaging and dual- or multiple-modality techniques. An improved understanding of apoptotic machinery as well as advances in imaging modalities in recent years have provided opportunities for imaging scientists to formulate microscopic and macroscopic imaging strategies that are based on well-defined molecular markers and/or physiological features. A large collection of apoptosis imaging probes and approaches have therefore been documented in preclinical and clinical studies.

In this review, we mainly discuss microscopic imaging assays and macroscopic imaging probes, ranging in complexity from simple attachments of reporter moieties to proteins that interact with apoptotic biomarkers, to rationally designed probes that target biochemical changes. Their clinical translation will also be our focus.

\section{Microscopic Imaging of Apoptosis}

Over the years, an extraordinary increase in research aimed at understanding the mechanisms and processes underlining apoptosis has led to a blossoming of fluorescence-based assays and labels for apoptotic markers readable in various formats, such as optical microscopy, flow cytometry, and microarrays, etc. In this section, we will review the chemistry of imaging probes that are suitable for assays of apoptosis at the cellular level and which, in most cases, use optical microscopy.

Fluorescent Annexin Based Assays. Annexin V is a small $35-36 \mathrm{kD}$ calcium-dependent protein with a potent high-affinity for PS $\left(K_{d}=0.1 \mathrm{nM}\right)$ [16]. In viable cells, PS is located in the inner membrane leaflet and not available for Annexin $\mathrm{V}$ binding. However, upon induction of apoptosis, it is translocated to the outer leaflet of the membrane, where it can bind with Annexin $\mathrm{V}$ in a $\mathrm{Ca}^{2+}$-dependent manner. Once bound to the PS-expressing membrane, the structure of Annexin $\mathrm{V}$ translates from monomers to trimers, which assemble in a two-dimensional lattice covering the PS-expressing surface via trimer-trimer interactions [17]. Annexin V conjugates are highly fluorescent and provide quick and reliable detection methods for studying the externalization of PS and serve as an indicators of early stages of apoptosis. These reagents must be applied to or injected into live cells or tissues for more than $15 \mathrm{~min}$ before washing and fixation. This si applicable to cells in culture and young embryos or injection into the circulation of older embryos $[18,19]$. However, PS also appears on the necrotic cell surface and leads to false positive signals. To overcome this, the combination of nucleic acid stains such as propidium iodine (PI) and Annexin V provide an option to distinguish viable, early apoptotic, late apoptotic and necrotic cells simultaneously via optical microscopy or flow cytometry.

In live cell imaging experiments, separate steps are required for binding of fluorescent Annexin V probes to apoptotic cells and subsequent removal of the unbound protein to minimize the background fluorescence before analysis. Therefore, reported Annexin V-based probes are suboptimal for live cell imaging. To circumvent these problems, pSIVA (Polarity Sensitive Indicator of Viability \& Apoptosis), an Annexin XII based, polarity sensitive probe was developed for the spatiotemporal analysis of apoptosis and other forms of cell death [20,21]. pSIVA was designed by engineering cysteine mutations at residues 101 and 260 in membrane-binding loops of an Annexin B12 plasmid construct, and conjugating the recombinant pSIVA protein to the polar sensitive dye IANBD, which fluoresces only when pSIVA is bound to the cell membrane. pSIVA's membrane bind- 
ing-dependent fluorescence and reversible binding properties are technological advancements in detecting PS exposure that are superior to Annexin V conjugates for gaining additional information on cell death/cell survival processes [22].

Chromogenic Caspase Substrate Based Assays. Caspases, a family of cysteine dependent aspartate-directed proteases, play a key role during the process of apoptosis. Most apoptotic signaling pathways converge on the activation of intracellular caspases and generate a complex biochemical cascade that propagates death signaling [23]. Due to the central role of caspases in the process of apoptosis, many types of caspase inhibitors and substrates with specificity for different members of the caspase family have been constructed for early detection of apoptosis. Based on these specific caspase inhibitors and substrates, a subset of assays have been developed for monitoring caspase activity. Fluorescently labeled DEVD peptides, widely used for caspase-3/-7 activity assays, release a fluorescent reporter that may be monitored by optical microscopy (with appropriate excitation and emission settings) when cleaved by caspase-3. In the case of DEVD-NucView 488 caspase-3 substrate, a highly negatively charged DEVD peptide is attached to a DNA-binding dye to make the dye unable to bind to DNA and thus unable to produce fluorescence in the presence of DNA. The substrate can rapidly cross cell membranes into the cell cytoplasm, and subsequently be cleaved by caspase- 3 to release the high-affinity DNA dye NucView 488. The released DNA dye migrates to the cell nucleus to stain the nucleus with bright green fluorescence. Therefore, this bifunctional substrate detects caspase-3 in an apoptotic cell, as well as stains the cell nucleus, which is known to undergo morphological change during the apoptotic process. As apoptotic cells in the same cell population may differ in their onset times for different apoptotic events, it is important to be able to follow these events independently in real-time, so that the interrelations among the events can be better understood. DEVD-NucView 488 caspase-3 substrate combined with other fluorescent probes has been constructed for studying the temporal and spatial relations among the various events by fluorescence microscopy [24].

Lipophilic Cationic Dye Based Assays. Mitochondria, one of the sources of signals that initiate apoptosis, plays a key role in apoptotic cell death. Depending on the potential stimulus, a series of mitochondrial dysfunctions can trigger the initiation of apoptosis [25]. One of the earliest characteristics of the mitochondrial dysfunction is the collapse of the mitochondrial transmembrane potential that occurs following induction of apoptosis. Therefore, it has been of growing interest to assess mitochondrial membrane potentials in intact cells. Cossarizza et al. reported a strategy for monitoring mitochondrial membrane potential changes in intact, living cells by employing 5,5',6,6'-tetrachloro-1,1',3,3'-tetraethylbenzimidazol-car bocyanine iodide (JC-1), a lipophilic cationic fluorescent dye that exists in a monomeric form, emitting at $527 \mathrm{~nm}$ after excitation at $490 \mathrm{~nm}[26,27]$. However, in the presence of a high mitochondrial membrane potential, JC-1 forms so-called J-aggregates that are accompanied by a large red shift in emission (590 nm) [28]. Therefore, the dye stains the mitochondria of healthy cells bright red; but, in apoptotic cells, JC-1 cannot accumulate within the mitochondria due to the collapse of mitochondrial membrane potential and remains in the cytoplasm in a green fluorescent monomeric form. Hence, it is easy to distinguish apoptotic cells that display primarily green fluorescence from healthy cells, which show red and green fluorescence. In addition, other fluorescent dyes such as TMRE or TMRM (Tetramethyl Rhodamine Ethylor Methyl-ester), and Rhodamine 123 can also be used to measure the mitochondrial membrane potential [29].

TdT-mediated dUTP Nick End Labeling (TUNEL) Assays. The fragmentation of DNA, known as a "DNA ladder", is another accepted indicator of apoptosis [30]. Labeling DNA fragments is a promising assay for detecting apoptotic cells [31]. Since the original description by Garvrieli, Sherman, and Ben-Sasson in the early 1990s, the TdT mediated dUTP-biotin nick end labeling (TUNEL) assay has become one of the most widely used methods for detecting DNA fragmentation during apoptosis [32]. The assay relies on the presence of nicks in the DNA which can be identified by terminal deoxynucleotidyl transferase or TdT. This method has subsequently been improved significantly and performed correctly when detecting apoptotic cells in the last phase of apoptosis. Several new methods utilize dUTPs modified by fluorophores or haptens, including biotin or bromine, which can be detected directly in the case of a fluorescently-modified nucleotide (i.e., fluorescein-dUTP), or indirectly with streptavidin or antibodies, if biotin-dUTP or Br-dUTP are used, respectively [33]. An alternative strategy is to use 5-ethynyl-2'-deoxyuridine (EdU), a dUTP modified with an alkyne. This small, bio-orthogonal functional group enables the nucleotide to be more readily incorporated by TdT than other modified nucleotides, as well as detected by a fluorescent azide that covalently reacts with the alkyne group via "click chemistry" [34]. This method is faster and more specific than other assays and doesn't require DNA denaturation [35]. 
Other Assays. ApoSense is a family of low molecular weight compounds, designed to address the challenge of molecular imaging of apoptosis. Since they interact with externalized PS residues on the cell surface, the molecules are perturbed membrane preferentially binding compounds comparable to Annexin $\mathrm{V}$ [36]. The compounds do not cross the plasma membrane of an intact, viable cell. However, in cells in the early stages of apoptosis, they perform selective passage through the membrane and accumulate in the cytoplasm. Uptake of ApoSense compounds during apoptosis occurs in parallel with acquisition of Annexin $\mathrm{V}$ binding, activation of caspases and the collapse of mitochondrial membrane potentials. The uptake of ApoSense precedes the loss of membrane integrity, as proven by PI exclusion. In vitro and ex vivo studies have demonstrated that dansyl compounds bearing amino acid moieties such as DDC ( $\mathrm{N}, \mathrm{N}^{\prime}$-didansyl-L-cystine) are selectively bound to apoptotic cells [37]. These studies illustrate its applicability as a diagnostic imaging agent enabling real-time accurate detection of apoptosis. Now, DDC has been developed for Apo-TRACE assays suitable for imaging apoptosis under fluorescence microscope or flow cytometry.

Rapid progress and continued interest in apoptosis have spurred the development of new assays and the revival of old ones. As shown in Table 1, the various apoptosis assays have different strengths and limitations in specific applications. Notably, no matter how appropriate and well accepted the assay is, it is always recommended that a second assay using a different principle be used to confirm the results of apoptosis detection.

\section{Macroscopic Imaging of Apoptosis}

Although the accumulated knowledge about the biology of apoptosis has resulted in microscopic imaging methods that have contributed to better understanding of the apoptotic process, these are primarily in vitro or ex vivo methods and are thus invasive and set limitations to many follow-up studies. More sophisticated methods with the requisite targetability and pharmacokinetics are needed to detect apoptosis in living cells, experimental animals and, ultimately, humans. In this section, various well-defined imaging probes for macroscopic imaging will be presented, including those for cell surface targets such as plasma membrane phospholipids, cell surface exposed histones, membrane potentials and those for intracellular targets such as caspases, mitochondrial membrane potentials, etc.

Radionuclide Imaging Probes. Despite rapid progress in a number of imaging modalities, nuclear imaging remains the premier clinical method. Simi- larly to computed tomography (CT), modern nuclear imaging techniques rely on the rotation of detector arrays around the subject of investigation. With this approach, the position and concentration of a radionuclide marker introduced into an animal or patient can be calculated. Unlike CT, however, nuclear medicine imaging involves the administration of radioactively labeled tracers, which decay over time by emitting gamma rays that can be detected by a PET or SPECT scanner, in conjunction with rigorous reconstruction algorithms [39]. The development of SPECT and PET, combined with the synthesis of novel radiolabeled tracers specific for different biochemical targets, launched the field of nuclear medicine into a new era of molecular imaging. A critical step in the development of tracers for nuclear imaging is the radiolabeling process. Due to the characteristics of short-lived radioisotopes, the labeling, purification, and characterization of radiolabeled molecules need to be performed in a restricted time window. This limits the options of the candidate chemistry. Various strategies have been developed that allow efficient labeling with clinically useful radioisotopes via a chelating moiety or prosthetic group. The chemistry of various convenient and efficient radiolabeling strategies, as well as recently developed radiolabeled probes for apoptosis targeting in vivo will be discussed here.

Table 1. Pros and Cons of Major Microscopic Assays for Apoptosis [38].

\begin{tabular}{|c|c|c|}
\hline Assay & Pros & Cons \\
\hline Annexin V & $\begin{array}{l}\text { Detects earlier apop- } \\
\text { tosis; } \\
\text { Allows double or } \\
\text { triple labeling; } \\
\text { Convenient to use }\end{array}$ & $\begin{array}{l}\text { Limited resources; Expensive; } \\
\text { Slow clearance; } \\
\text { More complicated synthesis and } \\
\text { isolation; } \\
\text { Non-specific interactions with the } \\
\text { parts of cells producing high back- } \\
\text { ground signal; } \\
\text { Annexin V binds to the PS which is } \\
\text { not a unique characteristic of apop- } \\
\text { tosis and also occurs in necrosis; } \\
\mathrm{Ca}^{2+} \text { dependence }\end{array}$ \\
\hline $\begin{array}{l}\text { Caspase } \\
\text { Activity }\end{array}$ & $\begin{array}{l}\text { Easy preparation; } \\
\text { Low background } \\
\text { interference; } \\
\text { Quantitative; } \\
\text { Easy to use }\end{array}$ & $\begin{array}{l}\text { Indirect approach; } \\
\text { Cannot detect specific cells or tissues } \\
\text { where the apoptosis is independent } \\
\text { of expression of caspases; } \\
\text { Need high levels of apoptosis }\end{array}$ \\
\hline $\begin{array}{l}\text { Mitochondrial } \\
\text { Potential }\end{array}$ & $\begin{array}{l}\text { Assay used in living } \\
\text { cells }\end{array}$ & $\begin{array}{l}\text { Mitochondrial events occur in } \\
\text { non-apoptotic pathways; } \\
\text { Mitochondrial events take place in } \\
\text { apoptosis and necrosis }\end{array}$ \\
\hline TUNEL & $\begin{array}{l}\text { High sensitivity; } \\
\text { Specificity for apop- } \\
\text { totic cells; } \\
\text { Commonly used and } \\
\text { well-accepted assay; } \\
\text { Can be used in whole } \\
\text { mounts of thin tissues }\end{array}$ & $\begin{array}{l}\text { Expensive; Time-consuming; } \\
\text { Often requires complicated pro- } \\
\text { cessing; } \\
\text { Possible false positives }\end{array}$ \\
\hline
\end{tabular}




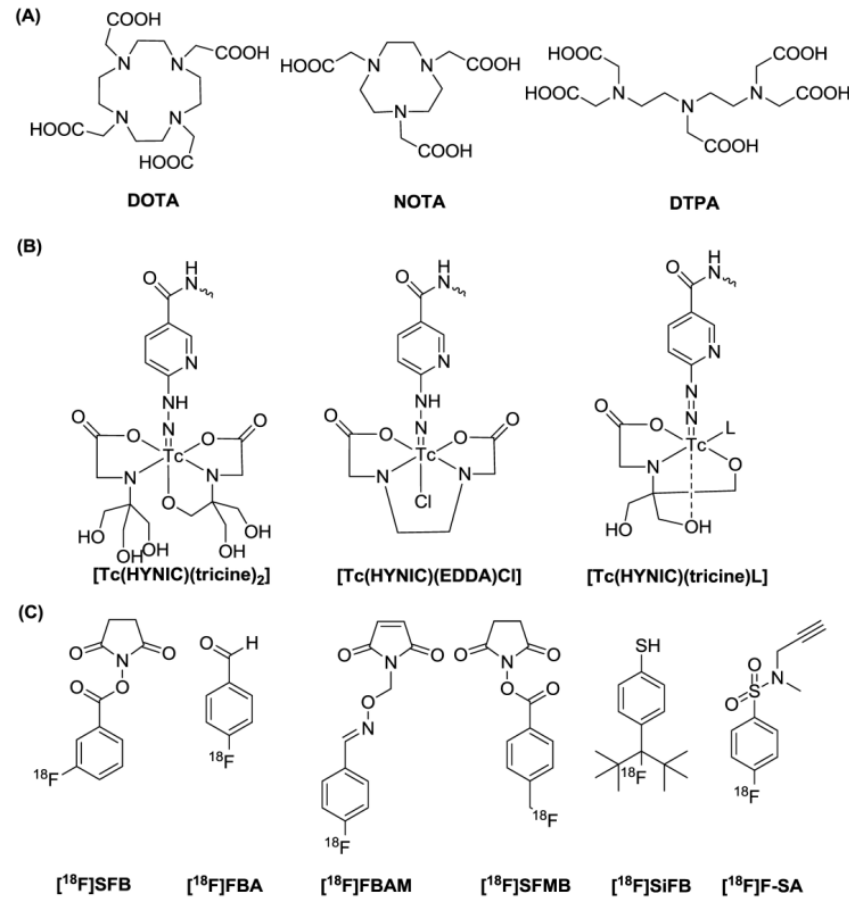

Figure 1. Representative radiolabeling strategies: (A) macrocyclic chelators, (B) Tc chelating agents and (C) $18 \mathrm{~F}$ synthons.

Radionuclide Labeling Strategies. There are various radiolabeling strategies available to incorporate a radionuclide into a probe molecule (Figure 1). The choice of technique for a radiochemist depends primarily on the radionuclide used [40]. For instance, since many metallic radionuclides possess the ability to form stable complexes with chelating agents, radioactive metals are often labeled via complexation with a chelator, thus allowing further conjugation with probe molecules. Metal isotopes, including ${ }^{64} \mathrm{Cu},{ }^{68} \mathrm{Ga}$ and ${ }^{111}$ In are introduced to the tracers mainly with the aid of certain polyaminopolycarboxylic ligands, such as 1,4,7,10-tetraaza-cyclodecane-1,4,7,10-tetraacetic acid (DOTA), 2,2',2'”-(1,4,7-triazacyclononane-1,4,7triyl)triacetic acid (NOTA) and diethylene triamine pentaacetic acid (DTPA). These chelators are efficient in coordinating the metals with all of the amino groups and some of the carboxyls. The multiple bonding sites lead to high binding strengths. Metals such as $99 \mathrm{~m}$ Tc can be efficiently chelated by other chelating groups. Although bare ${ }^{99 \mathrm{mTc}}$ can complex with polydentate chelators, such as boronic acid adducts or DTPA, the more favorable forms are $[\mathrm{Tc}=\mathrm{O}]^{3+}$ or Tc-6-hydrazinopyridine-3-carboxylic acid (HYNIC), which possess better stability. Various chelators with a combinational form of $\mathrm{N}_{\mathrm{x}} \mathrm{S}_{4-\mathrm{x}}$ have proved effective in binding with $\left[\mathrm{Tc}_{\mathrm{c}}=\mathrm{O}\right]^{3+}$, resulting in a square pyramidal structure with $\mathrm{Tc}$ in the center [41]. ${ }^{18} \mathrm{~F}$ has so far been the most utilized radioisotope in PET imaging. Compared to the radiometal-labeling method, where the labeling process is no more than an instan- taneous coordination, the ${ }^{18} \mathrm{~F}$ fluorination is far more complicated. There are generally two forms of ${ }^{18} \mathrm{~F}$ precursors, $\left.{ }^{18} \mathrm{~F}\right] \mathrm{F}$ (such as $\mathrm{K}\left[{ }^{18} \mathrm{~F}\right] \mathrm{F}$ and $\mathrm{Cs}\left[{ }^{18} \mathrm{~F}\right] \mathrm{F}$ ) and $\left[{ }^{18} \mathrm{~F}\right] \mathrm{F}_{2}$ or its derivative (such as acetyl hypofluorite $\left.\left(\mathrm{CH}_{3} \mathrm{COO}\left[{ }^{18} \mathrm{~F}\right] \mathrm{F}\right)\right)$. Although there are reports of using these two precursors for direct peptide labeling, generally these approaches are regarded as inefficient and lacking chemoselectivity, and are rarely employed. Practically, it is more common to convert the ${ }^{18} \mathrm{~F}$ precursors to certain forms of ${ }^{18} \mathrm{~F}$-labeled prosthetic groups (called synthons) and to use those synthons for peptide labeling. Due to the specificity of probe molecules for targets, attaching a bulky radiolabeled chelating group or a prosthetic group may influence the biological activity of the probe molecules. Therefore, site-specific radiochemistry is needed and important for the preparation of biologically active probes [42].

Radiolabeled Protein Probes. Annexin V-PS binding is one of the most successful and widely applied strategies in apoptosis imaging. By coupling different radioactive isotopes to the Annexin V molecule, visualization of PS in vivo in animal models or even in patients using SPECT or PET can be performed. An overview of the radioligands used for imaging PS is given in Table 2. ${ }^{99} \mathrm{mTc}$-labeled Annexin $\mathrm{V}$ is by far the most extensively investigated and broadly used apoptosis-detecting radioligand to date. Over the past years, a wealth of $99 \mathrm{~m} T \mathrm{c}$-Annexin $\mathrm{V}$ radioligands have been developed by different groups using various types of chelators and co-ligands, each resulting in a different biological behavior [62-64]. 99mTc-4,5-bis(thioacetamido)pentanoyl-Annexin V (99mTc-BTAPAnnexin V) was the first ${ }^{99 m T c-A n n e x i n ~ V ~ p r o b e ~ t o ~ b e ~}$ described and evaluated in vivo in animals and patients [44, 65-68]. However, due to the elaborate and time-consuming procedures but relatively low radiochemical yields, an improved method was needed. As an alternative radiolabelling approach for Annexin $\mathrm{V}$, in 1998, Blankenberg et al. [43] were the first to describe the preparation of $99 \mathrm{~m}$ Tc-hydraziononicotinamide-Annexin V (99mTc-HYNIC-Annexin V) using the HYNIC technology, originally developed by Abrams et al. [69] The preparation is performed by synthesis of an activated hydrazino-nicotinamide (HYNIC) ligand, which is a nicotinic acid analogue with a bifunctional chelator capable of binding to the $\mathrm{NH}_{2}$-terminal amino acid and lysine residues of proteins on the one hand and of sequestering $99 \mathrm{mTc}$ on the other, followed by conjugation to human rh-Annexin $\mathrm{V}$ and then labeled with $99 \mathrm{~m} \mathrm{Tc}$ using tricine as co-ligand in the presence of stannous ions (Figure 2). The HYNIC-Annexin V conjugate proved to be a stable complex and allowed fast and efficient labelling with $99 \mathrm{mTc}$. Compared with 99mTc-BTAP-Annexin V, 
the formulation of $99 \mathrm{mTc}-\mathrm{HYNIC}$-Annexin $\mathrm{V}$ is much simpler and faster, requiring substantially lower amount of starting activities (1.11-1.48 GBq). All of these advantages make 99mTc-HYNIC-Annexin V much more suitable for routine production and fast application in a clinical setting. Undoubtedly, the development of $99 \mathrm{mTc}-\mathrm{HYNIC}$-Annexin V can be considered as a benchmark in the field of apoptosis imaging since this tracer is by far the most extensively investigated and best characterised apoptosis detecting radioligand [70-74]. At present, 99mTc-HYNIC-Annexin V is the only apoptosis-detecting radioligand that is currently being investigated in phase II/III trials in patients with non-small-cell lung cancer [75, 76] and is likely to reach the stage of commercialization for routine use in nuclear medicine. However, this method is rather non-specific as any of the $-\mathrm{NH}_{2}$ groups could be targeted. Recently, a cys-Annexin $\mathrm{V}$ with a single cysteine-residue at its concave side has been developed by site-directed mutagenesis to allow conjugation through thiol-chemistry without affecting its apoptotic cell binding properties and was derivatized with HYNIC in a 1:1 stoichiometry [47]. Preliminary in vivo evaluation of this $99 \mathrm{mTc}-\mathrm{HYNIC}$-cys-Annexin V derivative shows apoptosis avidity similar to the 1st generation 99mTc-HYNIC-Annexin V [45, 77]. Annexin $\mathrm{V}$ and its mutants have also been designed for specific

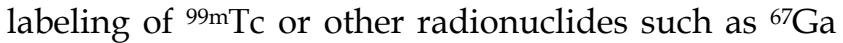
and ${ }^{111}$ In using the same methodology [48-52, 78-80]. Nevertheless, because of better resolution and the possibility of absolute quantitation, PET imaging of apoptosis could be superior to the SPECT approach in practice. Only a few methods have been published so far dealing with ${ }^{18} \mathrm{~F}$-labelling of Annexin V. The latest work presents a site-specific labeling of Annexin $\mathrm{V}-128$, a mutant form of Annexin V containing a single cysteine residue at the $\mathrm{NH}_{2}$ - terminus of Annexin $\mathrm{V}$, with the thiol-selective prosthetic group $\mathrm{N}-\left\{4-\left[\left(4-\left[{ }^{18} \mathrm{~F}\right]\right.\right.\right.$ fluorobenzylidene)aminooxy]butyl\}male imide $\left(\left[{ }^{18} \mathrm{~F}\right] \mathrm{FBABM}\right)$, which was synthesized in a two-step, one-pot method with an average yield of $23 \%$ and specific activities of $222 \mathrm{GBq} / \mu \mathrm{mol}$ (Figure 3A) [54]. Another labelling strategy uses the $\mathrm{NH}_{2}$-targeting active ester $\mathrm{N}$-succinimidyl 4-[18F]fluorobenzoate $\left(\left[{ }^{18} \mathrm{~F}\right] \mathrm{SFB}\right)$. The first fully automated synthesis for ${ }^{18} \mathrm{~F}$-Annexin $\mathrm{V}$ was developed by Zijlstra et al. via a four-step procedure with a radiochemical yield up to $20 \%$ (specific activity more than $35 \mathrm{GBq} / \mu \mathrm{mol}$ ) within $90 \mathrm{~min}$ (Figure 3B) [81]. Subsequently, they showed the potency of ${ }^{18} \mathrm{~F}$-Annexin $\mathrm{V}$ as a candidate for apoptosis imaging comparable to that of $99 \mathrm{~m} T c-A n n e x i n ~ V$ and the low uptake of ${ }^{18} \mathrm{~F}-\mathrm{Annexin} \mathrm{V}$ in the liver, spleen and kidneys, superior to ${ }^{99 \mathrm{~m} T c-A n n e x i n ~} \mathrm{~V}$ [82]. In addition, our group also employed $\left[{ }^{18} \mathrm{~F}\right] \mathrm{SFB}$ as the ${ }^{18} \mathrm{~F}$-labeled radiosynthon of choice for the synthesis of ${ }^{18} \mathrm{~F}$-Annexin $\mathrm{V}$ to visualize and evaluate apoptosis induced by doxorubicin in a human head and neck squamous cell cancer UM-SCC-22B tumour xenograft model [83]. The apoptosis was clearly visualized by ${ }^{18} \mathrm{~F}$-Annexin $\mathrm{V}$ PET with a peak tumor uptake at day 3 after treatment started, which was significantly higher than that in the untreated tumours (Figure 4).

Other PS-binding proteins have also been labeled with radionuclides for imaging apoptosis. The C2A domain of synaptotagmin I, a neural protein with $\mathrm{Ca}^{2+}$-dependent PS binding capacity, has been identified. Typically, the C2A domain is expressed and used as a recombinant glutathione-S-transferase (GST) fusion protein. The PET counterpart of C2A-GST $\left({ }^{18} \mathrm{~F}-\mathrm{C} 2 \mathrm{~A}-\mathrm{GST}\right)$ was prepared by labeling C2A-GST with $\left[{ }^{18} \mathrm{~F}\right] \mathrm{SFB}$ with more than $95 \%$ radiochemical purity and the stability for $4 \mathrm{~h}$ after formulation [59]. Despite the distinct structural differences between the C2A domain and Annexin V, the C2A domain can be labeled as efficiently with $\left[{ }^{18} \mathrm{~F}\right] \mathrm{SFB}$ as can Annexin V. Moreover, ${ }^{18} \mathrm{~F}-\mathrm{C} 2 \mathrm{~A}-\mathrm{GST}$ was able to detect apoptosis similarly to ${ }^{18} \mathrm{~F}$-Annexin $\mathrm{V}$ in the same tumor cells and animals. Besides, the glycoprotein lactadherin (also known as MFG-E8, PAS-6/7) is also capable of specifically binding to PS in a

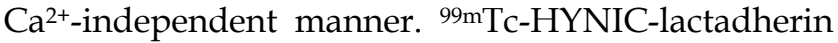
conjugates showed the same phospholipid binding properties as lactadherin, and biodistribution studies demonstrated rapid clearance from the blood and accumulation in the liver $[61,84]$. A recent study in pigs found that in contrast to $99 \mathrm{mTc}$-Annexin V, 99mTc-lactadherin has a low renal uptake, making it possible to image apoptosis in the kidneys [85].

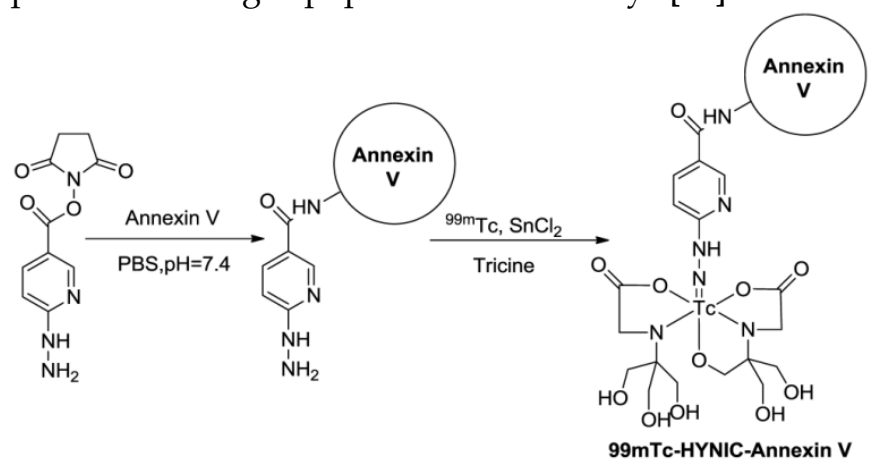

Figure 2. Radiochemistry of $99 \mathrm{mTc}-\mathrm{HYNIC}-$ Annexin V. 
Table 2. An Overview of the Radioligands Used for Imaging PS during Aapoptosis.

\begin{tabular}{|c|c|c|c|c|}
\hline Radiopharmaceutical & Radionuclide & $\begin{array}{l}\text { Half-life } \\
\text { Time }\end{array}$ & Labeling Intermediates & Ref. \\
\hline 99mTc-HYNIC-Annexin V & $99 \mathrm{mTc}$ & $6.02 \mathrm{~h}$ & & 43 \\
\hline 99mTc -BTAP-Annexin V & ${ }^{99 \mathrm{mTC}}$ & $6.02 \mathrm{~h}$ & & 44 \\
\hline $\begin{array}{l}\text { 99mTc -HYNIC-cys- } \\
\text { Annexin V }\end{array}$ & $99 \mathrm{mTc}$ & $6.02 \mathrm{~h}$ & & 45 \\
\hline 99mTc -MAG3-Annexin V & ${ }^{99 \mathrm{mTC}}$ & $6.02 \mathrm{~h}$ & & 46 \\
\hline 99mTc -EC-Annexin V & ${ }^{99 \mathrm{mTc}}$ & $6.02 \mathrm{~h}$ & & 47 \\
\hline 99mTc -N2S2-Annexin V 118 & ${ }^{99 \mathrm{mTC}}$ & $6.02 \mathrm{~h}$ & & 48 \\
\hline${ }_{99 \mathrm{mTc}}-(\mathrm{CO})_{3}$-Annexin V 123 & $99 \mathrm{mTc}$ & $6.02 \mathrm{~h}$ & & 49 \\
\hline $\begin{array}{l}\text { 111In DTPA-PEG- } \\
\text { Annexin V }\end{array}$ & 111In & $2.8 \mathrm{~d}$ & & 50,51 \\
\hline 67/68Ga- Annexin V & ${ }^{67 / 68} \mathrm{Ga}$ & $78.3 / 1.1 \mathrm{~h}$ & & 52,53 \\
\hline${ }^{18} \mathrm{~F}$-Annexin $\mathrm{V}$ & ${ }^{18} \mathrm{~F}$ & $1.83 \mathrm{~h}$ & & 54 \\
\hline 124I -MBP-Annexin V & 124I & $4.2 \mathrm{~d}$ & {$\left[{ }^{124} \mathrm{I}\right] \mathrm{NaI}$} & 55 \\
\hline${ }^{64} \mathrm{Cu}$-DOTA-Annexin V & ${ }^{64} \mathrm{Cu}$ & $12.7 \mathrm{~h}$ & & 56 \\
\hline${ }^{11} \mathrm{C}$ - Annexin V & ${ }^{11} \mathrm{C}$ & $20 \mathrm{~min}$ & {$\left[{ }^{11} \mathrm{C}\right] \mathrm{CH}_{3} \mathrm{I}$} & 57,58 \\
\hline${ }^{18} \mathrm{~F}-\mathrm{C} 2 \mathrm{AGST}$ & ${ }^{18} \mathrm{~F}$ & $1.83 \mathrm{~h}$ & & 59 \\
\hline 99mTc-C2AGST & $99 \mathrm{mTc}$ & $6.02 \mathrm{~h}$ & & 60 \\
\hline 99mTc-HYNIC-lactadherin & ${ }^{99 m \mathrm{mc}}$ & $6.02 \mathrm{~h}$ & & 61 \\
\hline
\end{tabular}


(A)

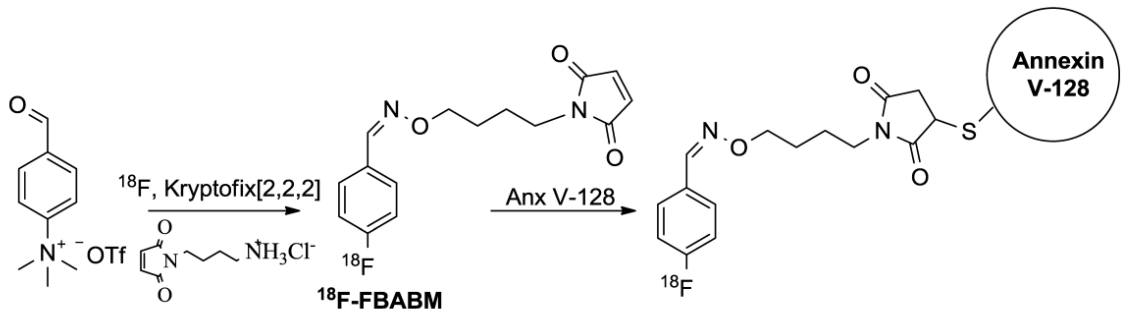

(B)

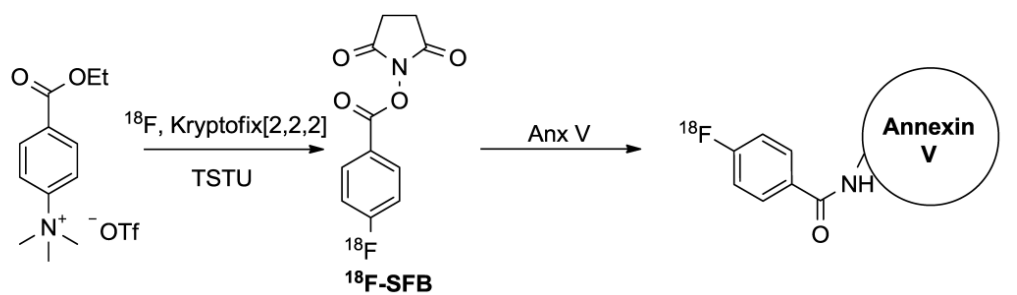

Figure 3. Different labeling strategies for the synthesis of $18 \mathrm{~F}-$ Annexin $\mathrm{V}$.

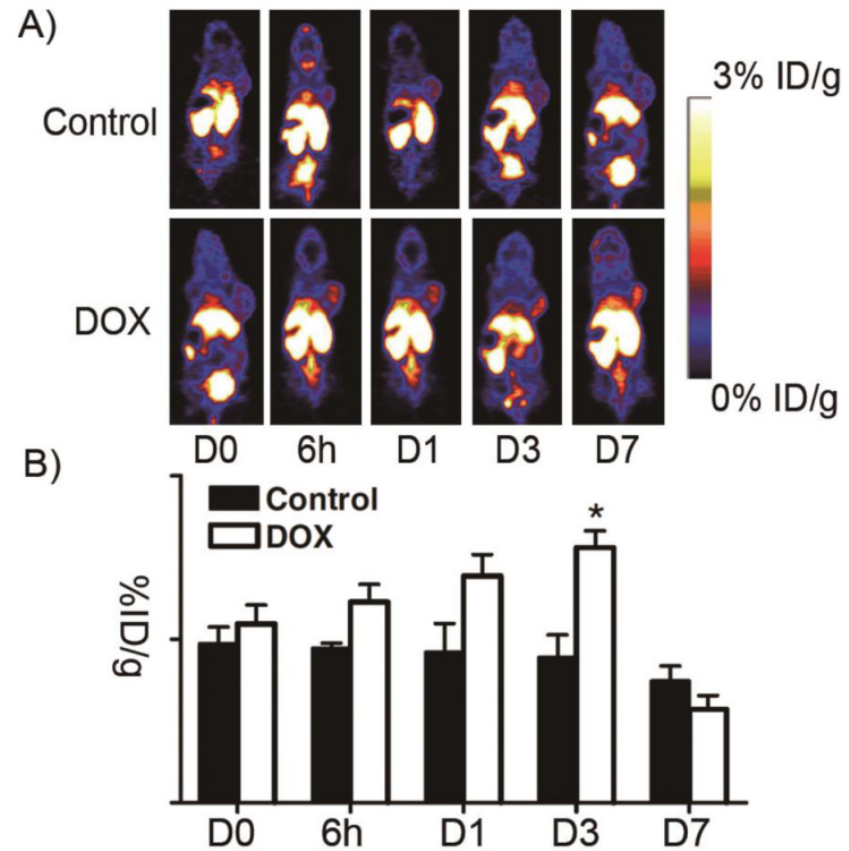

Figure 4. ${ }^{18 F-A n n e x i n ~} \mathrm{~V}$ PET imaging of UM-SCC-22B tumor-bearing mice with or without doxorubicin treatment. A) Representative decay-corrected whole-body coronal PET images at different time points after treatment started are shown.18F-Annexin $\mathrm{V}(3.7 \mathrm{MBq}, 100 \mu \mathrm{Ci})$ was injected via tail vein and 10 -min static scans were acquired at $1 \mathrm{~h}$ after injection. Tumors are indicated by arrows. B) Tumor uptake of $18 \mathrm{~F}-$ Annexin $\mathrm{V}$ was quantified from PET scans $(n=5)$. After doxorubicin treatment, tumor uptake increased to a peak at day 3 after treatment started $(p<0.05)$. (Adapted from Ref. [83] with permission.)

Radiolabeled Peptide Probes. Because protein probes have inherent defects, such as slow clearance rate, several radiolabeled peptide probes have been developed by various groups independently. Xiong et al identified a 14-mer peptide FNFRLKAGAKIRFG (PSBP) that was derived from the PS-binding site with PS binding affinity $K_{d} \sim 100 \mathrm{nM}$ [86]. Preclinical models were used to determine the effectiveness of $99 \mathrm{mTc}$ labeled PSBP for the early assessment of treatment-induced apoptosis in comparison with widely clinically used 18 F-FDG [87]. Similar to PS, the appearance of phosphatidylethanolamine (PE) (20-40\% of total phospholipid) on the cell surface also appears to be a universal indicator of apoptosis. Duramycin, a 19-amino-acid, disulfide crosslinked peptide has been found to be capable of binding to PE with high affinity and high selectivity [88]. Duramycin is covalently modified with HYNIC and labeled with 99mTc using the tricine-phosphine coligand system. With its robust binding mechanism and favorable pharmacokinetic profile, the in vivo properties of $99 \mathrm{mTc}$-Duramycin are promising [89-91]. However, up to this point, HPLC purification is prerequisite for intravenous injection. Therefore, it would be desirable to attain high quality 99mTc-Duramycin without additional purification steps in a single-step kit formulation. Recently, a single-step kit formulation was developed for 99mTc-labeling of HYNIC-Duramycin [92]. An optimal formulation with tricine-to-TPPTS molar ratio of 10:1 was ultimately determined, which led to consistent production of $99 \mathrm{~m}$ Tc-Duramycin with high radiochemical purity without need of further purification. The radiopharmaceutical produced retained PE binding affinity and specificity, while its clearance properties and in vivo biodistribution were consistent with those in prior studies involving radioHPLC-purified preparation [91].

In addition to exposed PS and PE, recent studies indicated that the exposed histones on the cell surface can also be one of the characteristics of apoptosis [93]. Based on this, Wang et al. identified a CQRPPR hexapeptide (Apopep-1) using phage display technology, which targets the histone H1 exposed on the surface of apoptotic cells [94]. Modification of ApoPep-1 with radioactive iodine (124I) enabled PET imaging of tumor apoptosis in vivo. The uptake of 18F-FDG decreased only by 0.97 in drug-induced apoptosis of tumor, whereas the accumulation of ${ }^{124}$ I-ApoPep-1 
increased by 1.6 during the same time, indicating that early response of tumor to anti-cancer drugs could be monitored properly by radiolabeled ApoPep-1.

In other situations, radiolabeled peptides targeting caspases have also been employed to detect apoptosis. An initial study was conducted with the irreversible pan-caspase inhibitor Z-VAD-FMK [95]. This radioiodinated Z-VAD-FMK was analyzed with apoptotic Morris hepatoma cells, showing increased uptake in apoptotic cells but insufficient overall cell uptake. This could be ascribed to an intrinsic disadvantage of caspase inhibitors such as binding-site saturation. Enzyme substrates that leave the active site of an enzyme after cleavage result in a signal enhancement. One prerequisite, however, which has to be met, is the retention of the cleaved imaging agent [96]. Recently, Kolb et al. identified and validated ${ }^{18} \mathrm{~F}-\mathrm{CP} 18$, a DEVD (the caspase 3 substrate recognition motif) containing a substrate-based compound as an imaging tracer for caspase-3 activity in apoptotic cells (Figure 5) [97]. In vitro assays showed caspase-3-dependent uptake of ${ }^{18} \mathrm{~F}-\mathrm{CP} 18$ in apoptotic tumor cells, while the in vivo microPET imaging signal of ${ }^{18} \mathrm{~F}-\mathrm{CP} 18$ in xenograft tumors correlated with the ex vivo caspase-3/ 7 activities in these tumours [98]. Soon after, the biodistribution and radiation dosimetry of ${ }^{18} \mathrm{~F}-\mathrm{CP} 18$ in healthy volunteers was assessed using whole-body PET/CT scans [99]. ${ }^{18} \mathrm{~F}-\mathrm{CP} 18$ displayed strong uptake in both the bladder and the kidneys, indicating a rapid renal clearance. From the radiation dosimetry perspective, because of receiving the highest radiation dose, the urinary bladder wall was deemed the critical organ.

However, up to now, there has been no report on PET imaging of apoptosis using reporter gene systems [100]. As a proof of concept, we described a unique molecularly engineered cyclic herpes simplex virus type 1-thymidine kinase (cTK) reporter for real-time apoptosis PET imaging [101]. The cyclic PET reporter was developed by fusing two fragments of DnaE intein to neighboring ends of HSV1-TK connected with a substrate sequence for caspase- 3 recognition (Figure 6).

Radiolabeled Small Molecular Probes. Compared with protein and peptide probes, small molecules have advantageous clinical translation potentials, including amenable structural optimization and favorable pharmacokinetic properties such as organ distribution profiles, rapid diffusion rates and blood-pool clearance rates. Therefore, it is highly desirable to develop several classes of small molecule imaging probes with the same targeting capabilities as proteins. With this in mind, investigators have searched for small molecules that exhibit high selectivity and affinity for apoptotic cells. The group of
Smith and co-workers utilized zinc dipicolylamine (Zn-DPA) coordination complexes as an alternative approach for PS-targeting [102]. $\mathrm{Zn}^{2+}$ ions mediating cooperative association of the dipicolylamine ligand and the anionic head group of membrane-bound PS accounted for its targeting function [103-105], which is similar to the way that $\mathrm{Ca}^{2+}$ ions act as cofactors for membrane association of Annexin V. Recently, Wyffels et al. developed ${ }^{99 \mathrm{~m} T c}(\mathrm{CO})_{3}-\mathrm{ZnDPA}$ and $99 \mathrm{mTc}-\mathrm{HYNIC}-Z \mathrm{nDPA}$ to assess their potential for apoptosis imaging using SPECT [106]. The anti-Fas liver apoptosis and myocardial ischemia reperfusion injury mouse models demonstrated the ability of the 99mTc-labeled Zn-DPA coordination complexes to target apoptosis. To extend this molecular design strategy, Oltmanns et al. have developed a ${ }^{18} \mathrm{~F}$-labelled zinc-cyclen probe targeting apoptosis [107]. PET imaging in both radiation and taxol treated tumors models in vivo revealed higher levels of Zn-cyclen probe compared with the non-treated groups. However, high accumulation of Zn-DPA and Zn-cyclen probes in the liver and other organs occurred, which suggested that the pharmacokinetics need to be optimized before they can be considered for clinical trials. In addition, other radioisotopes such as ${ }^{111}$ In were used for labeling to further explore the potential of radiolabeled Zn-DPA coordination complexes for imaging apoptosis [108].

Another class of small molecule agents comprise the ApoSense family including DCC, NST-732 and dansyl-ML-10 with a key di-acid (typically a malonic acid) functionality that allows the probe to interact with externalized PS residues on the cell surface [109-112]. ${ }^{18}$ F-ML-10 is the first PET tracer for apoptosis that has advanced into the clinical stage of development, with promising results to date in several small scale clinical trials (Figure 7). Pre-clinical studies with ${ }^{18} \mathrm{~F}-\mathrm{ML}-10$ showed the cerebral uptake in the stroke area that well correlated with histologic evidence of cell death [113]. In a phase I trial on healthy volunteers, ${ }^{18} \mathrm{~F}-\mathrm{ML}-10$ manifested high stability in vivo and favorable biodistribution and dosimetry profiles [114]. In a phase IIa study, PET imaging of apoptosis of neurovascular cells has been achieved in patients with acute ischemic cerebral stroke. In patients with brain metastases treated with whole-brain radiation therapy, the uptake of ${ }^{18} \mathrm{~F}-\mathrm{ML}-10$ was shown on the PET scans. Voxel-based analysis showed a mean change in ${ }^{18} \mathrm{~F}-\mathrm{ML}-10$ in the volume of interest (VOI) of $69.9 \%$, ranging from $36.3 \%$ to $100 \%$, which correlated with the anatomic response evidence obtained by MRI 6-8 weeks after completion of therapy $[115,116]$. However, the radioiodinated version of ML-10, which showed a clearly $\mathrm{pH}$-dependent uptake in tumor cells both in vitro and in vivo, was not suitable for apoptosis 
imaging due to a poor acidosis effect in apoptotic cells [117]. This suggested that further studies are needed to fully elucidate the targeting mechanism of this probe family so that the probe structure can be rationally modified for specific apoptosis imaging applications [118].

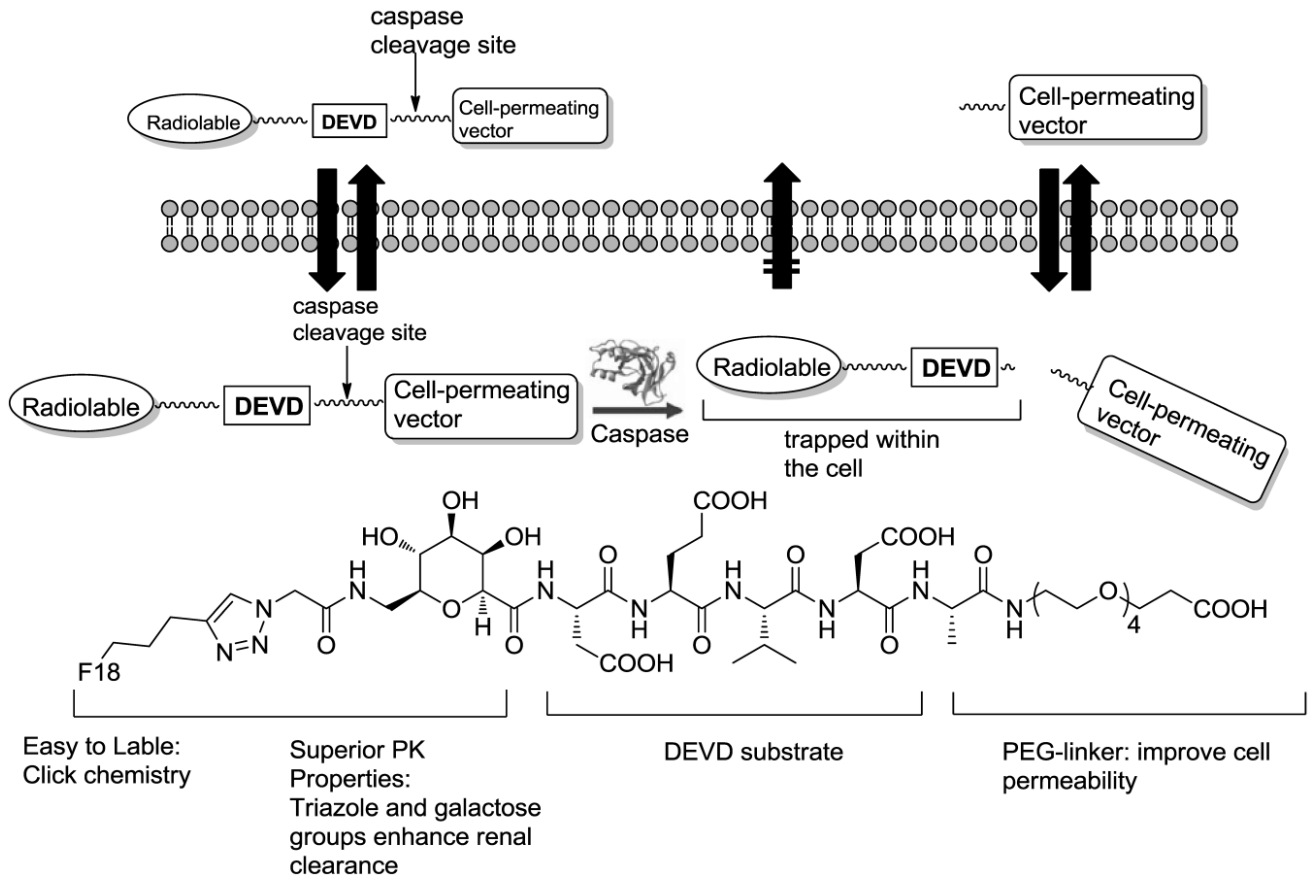

Figure 5. Design of caspase-3 substrate-based PET tracer DEVD-based CP18 and cleavage of CP18 by caspase-3.

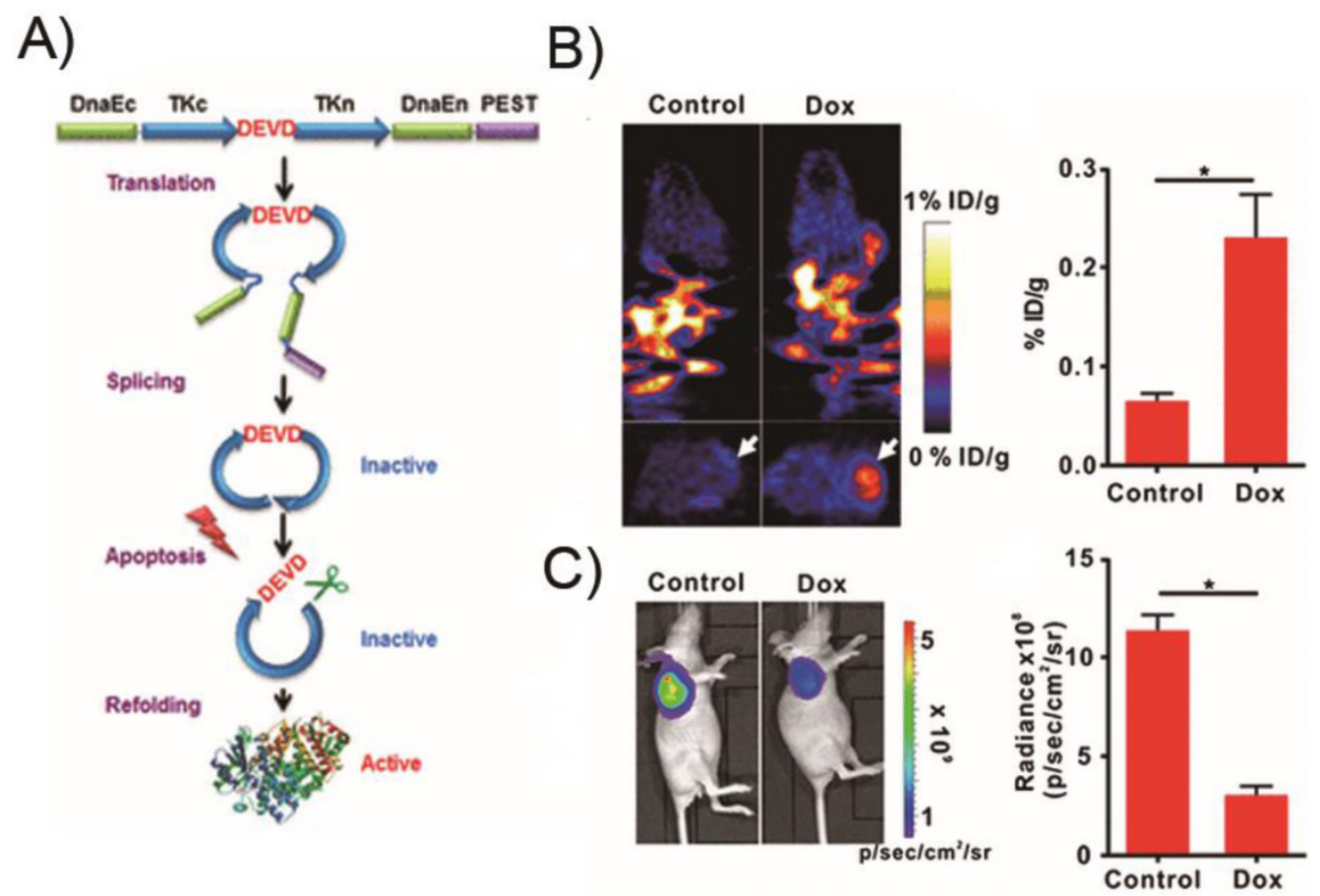

Figure 6. A cyclic HSV1-TK reporter for real-time PET imaging of apoptosis in mice models xenografted transfected cTK-Fluc cells. a) Schematic overview of the principle for monitoring apoptosis. The $\mathrm{N}$ and $\mathrm{C}$ termini of HSV1-TK are linked with DEVD, a substrate peptide of caspase-3. Upon caspase-3 activation during apoptosis, the DEVD sequence is cleaved and the cyclized TK restores its activity. b) In vivo PET imaging of apoptosis after Dox treatment. Representative coronal (upper) and transaxial (lower) micro-PET images of mice bearing cTK-Fluc tumors at $2 \mathrm{~h}$ postinjection of $18 \mathrm{~F}-\mathrm{FHBG}$ (11.1 MBq per mouse) after treatment with 10 $\mathrm{mg} / \mathrm{kg}$ of Dox for $72 \mathrm{~h} \mathrm{(n=6}$ per group) (left). The white arrows point to tumors. According, quantification of the PET signal over the tumor region (right), represented as a mean percentage injected dose per gram (\%ID/g). c) Representative BLI images of the same groups of mice after Dox treatment (left). $* P<0.05$. According, quantification of tumor BLI signal (right). $* P<0.05$. Results were representative data collected from independent duplicate experiments. (Adapted from Ref. [101] with permission.) 


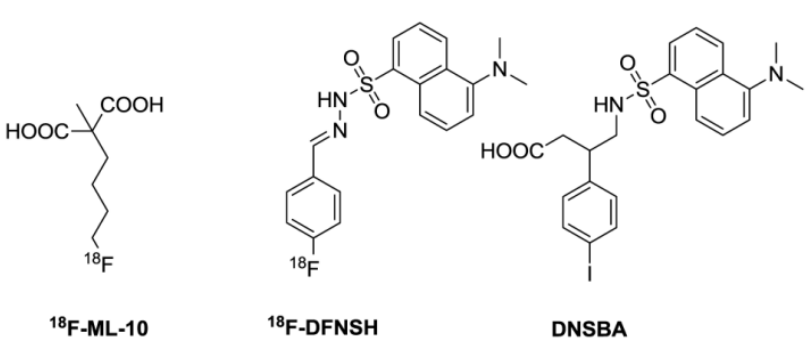

Figure 7. Chemical structures of representative small molecules.

Based on the dansyl moiety showing accumulation inside the cytoplasm of apoptotic cells, Zeng and his coworkers designed and synthesized a class of dansylhydrazone analogues for detecting apoptosis (Firure 7) [119-121]. The biological evaluation showed that these dansylhydrazone, including DFNSH, selectively bind to paclitaxel-induced apoptotic cancer cells. Subsequently, ${ }^{18} \mathrm{~F}-\mathrm{DFNSH}$ was synthesized and isolated in $50-60 \%$ radiochemical yields, based on $\left[\mathrm{K} / \mathrm{K}_{222}\right]^{18} \mathrm{~F}$, with a synthesis time of $50 \mathrm{~min}$. This straightforward preparation of fluorine-18 labels makes it a promising probe for PET imaging of apoptosis. More recently, the same group prepared 4-(5-dimethylamino-naphthalene-1-sulfonamido)-3-(4 -iodophenyl)-butanoic acid (DNSBA) with good yield [122]. The biological characterization demonstrated that DNSBA can be used to specifically and selectively detect apoptotic cancer cells at both early and late stages of apoptosis. Labeling of DNSBA with radioiodine (I-123, -124, and -131) to further explore the potential for SPECT and PET imaging of apoptosis is promising for further application.

On the other hand, an advance has recently been made with the introduction of small-molecule caspase inhibitors, based mostly on the isatin sulfonamide moiety [123-125]. The first evaluation of the isatin series for in vivo imaging of apoptosis was implemented by Zhou et al. using ${ }^{18}$ F-WC-II-89 [126]. The synthesis of ${ }^{18} \mathrm{~F}-\mathrm{WC}-\mathrm{II}-89$, shown in Figure 8, resulted in good yield (more than $70 \%$ ) with high radiochemical purity $(99 \%)$ and specific activity ( 55.5 $\mathrm{GBq} / \mu \mathrm{mol})$. In a rat model, ${ }^{18} \mathrm{~F}-\mathrm{WC}-\mathrm{II}-89$ showed approximately two-fold higher accumulation in liver and spleen in treated animals than in control groups as analyzed by both PET imaging and ex vivo biodistribution and this correlated well with caspase-3 activity. Another promising imaging agent of the isatin series was ${ }^{18} \mathrm{~F}-\mathrm{ICMT}-11$ and more in vitro and in vivo evaluations have been employed for caspase-3/7 imaging [127-130]. For clinical translation, an automated radiosynthesis of ${ }^{18} \mathrm{~F}-\mathrm{ICMT}-11$ was developed using a protected tosylate precursor and displayed high EOS yield in a short time with very high specific activity (Figure 9) [131,132]. Due to the promising mechanistic and safety profile of ${ }^{18} \mathrm{~F}-\mathrm{ICMT}-11$, the radiotracer has been selected as a candidate radiotracer by the QuIC-ConCePT consortium for clinical development [132]. Most recently, ${ }^{18} \mathrm{~F}-\mathrm{ICMT}-11$ was performed in healthy volunteers for biodistribution and radiation dosimetry [133]. After the administration, ${ }^{18} \mathrm{~F}-\mathrm{ICMT}-11$ accumulated in the liver and kidneys rapidly, followed by clearance through the renal and the hepatobiliary routes. The effective dose (ED) averaged over both men and women was estimated to be $0.025 \pm 0.004 \mathrm{mSv} / \mathrm{MBq}$ with good tolerance, which is within the range of other commonly used ${ }^{18} \mathrm{~F}$ PET tracers.

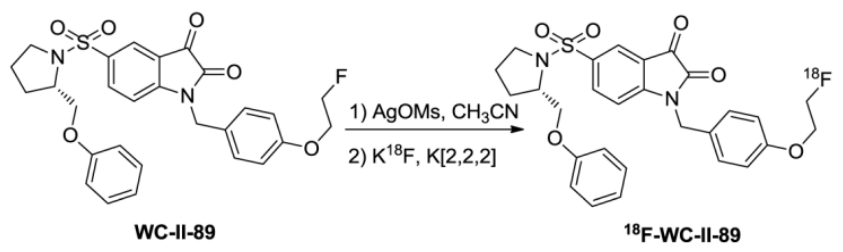

Figure 8. Radiosynthesis of $18 \mathrm{~F}-\mathrm{WC}-11-89$.

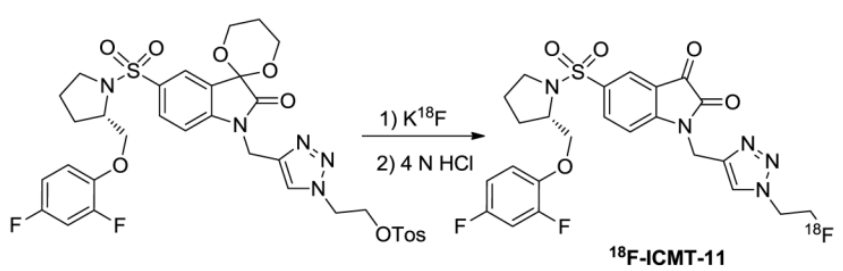

Figure 9. Labeling strategy for synthesis of $18 \mathrm{~F}-\mathrm{ICMT}-11$

In addition, several other classes of small molecular probes have been designed and employed for imaging apoptosis with different targeting. The ${ }^{18} \mathrm{~F}$-fluorobenzyl triphenylphosphonium cation $\left({ }^{18} \mathrm{~F}-\mathrm{FBnTP}\right)$ was developed to target the collapses of electrochemical proton gradient across the inner mitochondrial membrane at the early period of apoptosis [134]. The high sensitivity of ${ }^{18 F-F B n T P}$ to detect apoptosis in vitro and in vivo, and its capacity to report the progression over time of the metabolic defect may have important clinical implications in diseases other than cancer [135-137]. Nevertheless, in contrast to the increased signal observed with other PET apoptosis probes, these probes present a signal reduction on induction of apoptosis that are technically less attractive [138]. In view of the $90 \mathrm{kDa}$ heat shock protein (Hsp90) as a major inhibitor of apoptosis [139, 140], noninvasive imaging of this target is likely to have wide application in biological research and patient diagnosis and management. Recently, Park et al. described a peptide trivalent arsenical, 4-(N-(S-glutathionyl-acetyl)amino)phenyl-arsonous acid (GSAO), that rapidly accumulates in the cytosol predominantly by covalent cross-link with the highly conserved Cys-Cys motif ( $\mathrm{Cys}^{719}$ and $\mathrm{Cys}^{720}$ ) in the C-terminal domain of Hsp90 [141]. The abundance of 
Hsp90 in the cytosol allows for high accumulation of GSAO conjugates in apoptotic cells and therefore results in superior sensitivity and resolution of detecting apoptosis. Modification of GSAO with DTPA and ${ }^{111}$ In enables in vivo imaging of cell death in tumor models by SPECT/CT comparable to that of 99mTc-Annexin V.

Optical Imaging Probes. Microscopic optical imaging has traditionally been the gold standard for cellular imaging in molecular biology. Alongside the introduction of live cell fluorescence microscopy, a number of macroscopic optical imaging modalities have emerged. These macroscopic imaging techniques enable noninvasive following of molecules in real time at good spatial resolution (nanometer to millimeter range) and temporal resolution (microseconds to a few minutes), with high sensitivity (femto- to picomolar range) [142]. Recently developed optical imaging instruments and sophisticated optical imaging probes have provided noninvasive, real-time imaging of small animals at the whole-body, tissue, and cellular levels. Particularly, the combination of various near-infrared (NIR) fluorophores and ligands has significantly expanded and improved the performance of optical imaging systems. In this section, we will limit our discussions to the recent progress in the development of apoptosis-targeting NIR fluorescent probes and bioluminescence probes after a brief introduction to fluorophores and labeling strategies.

Fluorophore Labeling Strategies. By taking advantage of NIR optical imaging [143], concerted efforts to develop new NIR fluorophores and imaging probes have surged over the past decade. To date, a number of NIR fluorophores have been reported, and their reactive intermediates for bioconjugation are readily available (Figure 10). For instance, NIR fluorophores are provided in the forms of -NHS ester, -maleimide, and -hydrazide, with the targeting functional groups being amine, thiol, and carbonyl, respectively. However, NIR fluorophore molecules are sensitive to the environment, and their emission may vary with changes of $\mathrm{pH}$, solvent, and buffer components. This can be beneficial, as when the fluorophore and quencher are arranged in close proximity $(<10$ $\mathrm{nm}$ ), strong fluorescence quenching can be induced by fluorescence resonance energy transfer (FRET) and dark quenching mechanisms [144]. This principle has been employed in the design of activatable imaging probes, which are effective in monitoring enzyme-based pathological alternations. Bioluminescence resonance energy transfer (BRET) operates with biochemical energy generated by bioluminescent proteins to excite fluorophores and offers additional advantages over FRET for in vivo imaging [145]. Two kinds of apoptosis reporter genes have been reported in the literature in which either: i) luciferin loses its bioluminescence activity by changing structure or ii) the luminescence is quenched by forming luminescent donor and fluorescent acceptor protein pairs based on BRET. The remaining sections of this review discuss recently reported, highly sensitive inactivatable/activatable probes that combine various fluorophores with substrates, polymers, nanoparticles, and reporter genes to image apoptosis.

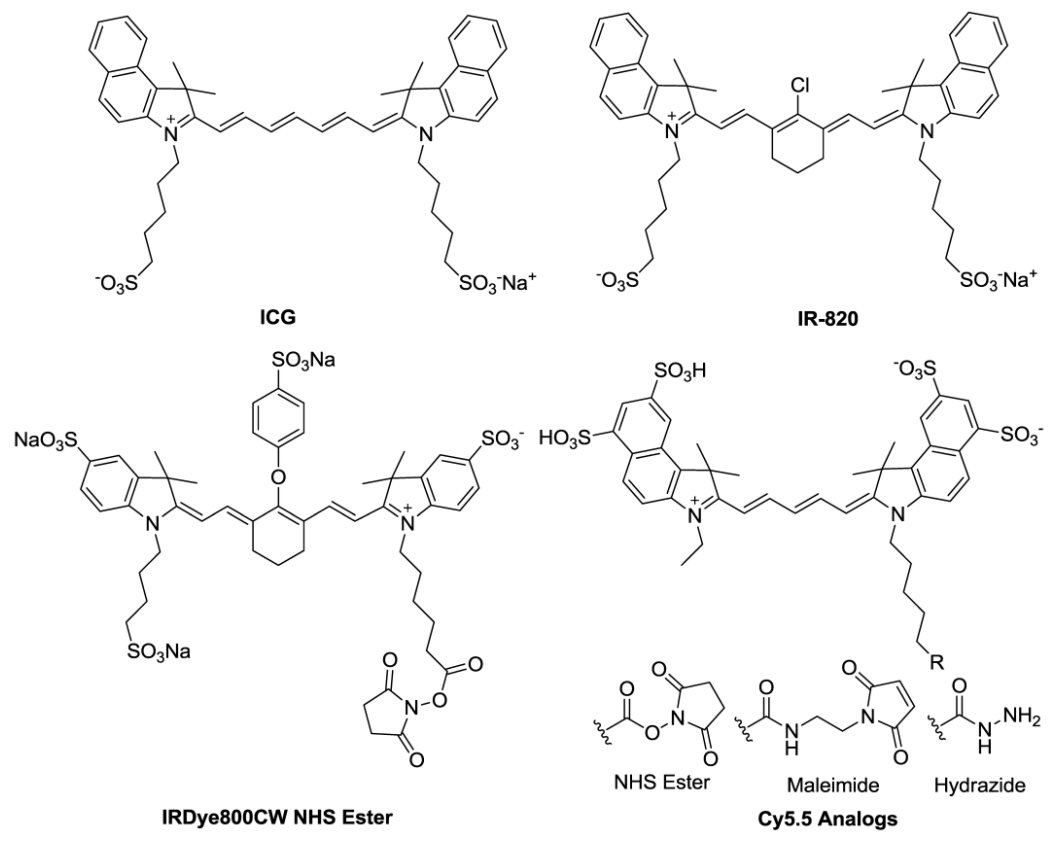

Figure 10. Chemical structures of commonly used NIR fluorophores. 
Fluorophore-Labeled Probes. As the first NIR probe for optical imaging in tumor apoptosis in vivo, Annexin $\mathrm{V}$ was labeled with the near infrared fluorescence dye, Cy5.5 [146]. Interestingly, the preparation of Cy5.5-Annexin V in an equimolar dye-to-protein ratio has PS-binding capability. However, Cy5.5-Annexin V probes modified with $>2$ dyes per protein did not bind to PS. In the tumor model the NIR fluorescence signal of PS-binding Cy5.5-Annexin $\mathrm{V}$ increased 2-3 folds after treatment compared to the control. To overcome the limitations of NIR imaging such as relatively low resolution and the lack of quantification, tomographic techniques have been recently developed that allow for quantitative three-dimensional imaging in deep tissues. Accordingly, Ntzachristos et al. demonstrated that tumor response to chemotherapy can be accurately resolved by fluorescence mediated tomography (FMT) using the PS-binding probe Cy5.5-Annexin V. They also observed at least a 10-fold increase of the fluorochrome-associated signal in treated tumors and a 7-fold increase in resistant tumors, each compared with corresponding control studies [147]. To mimic the apoptosis sensing function of Annexin $\mathrm{V}$, the conjugation of a Zn-DPA affinity group to a NIR fluorophore was developed $[148,149]$. The ability of fluorescently labeled Zn-DPA to target and identify apoptosis in vivo was validated in animal models.

A)

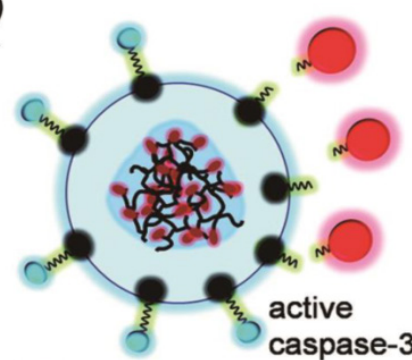

NIRF quenched polymeric nanoprobe for apoptosis imaging

B) (Apo-NP)

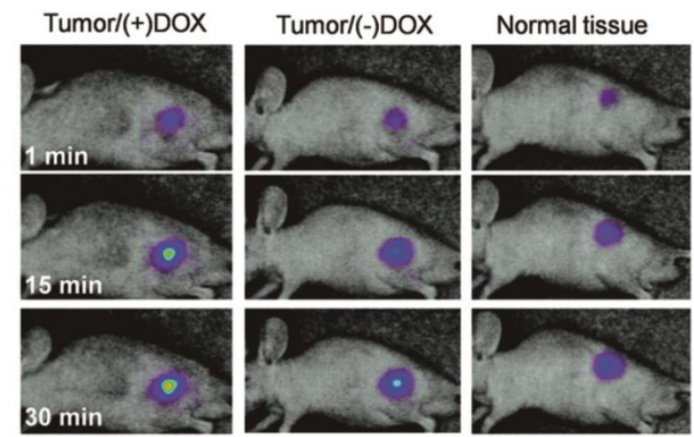

Figure 11. Real-time imaging of apoptosis with a polymeric nanoprobe. A) Schematic diagram of the caspase-3 activatable nanoprobe (Apo-NP). B) In vivo NIR fluorescence images of subcutaneous SCC7 tumor-bearing mice after intratumoral injection of the Apo-NP with or without pretreatment of doxorubicin ( $24 \mathrm{~h}$ before the probe injection). Only apoptotic tumors were clearly visualized. (Adapted from Ref. [158] with permission.)
Fluorophore-Quenched Activatable Probes. NIR fluorophore-labeled probes continuously emit signals and hence are "always on" [150]. The fundamental disadvantage of "always on" probes is that they emit signals regardless of their proximity or interaction with target tissues or cells, and as a result there is considerable background signal to contend with [151]. Recently, "activatable probes" or "smart probes" have become a particularly attractive platform for targeted optical imaging [152, 153]. These probes allow researchers to control and manipulate the outputs of maximized target signal and minimized background signal by altering the chemical environment. To target caspases, Bullok et al. prepared a small, membrane permeable probe, TcapQ647, consisting of a Tat permeation peptide sequence (Ac-rkkrrorrr), an effector caspase recognition sequence (DEVD), and an activatable dye pair of QSY 21/Alexa Fluor 647 [154]. The studies demonstrated that TcapQ647 is a sensitive, effector caspase-specific "smart" probe to monitor apoptosis [155, 156]. A similar probe design with a different cell-penetrating peptide sequence KKKRKV resulted in improved signal sensitivity with less cellular toxicity [157].

Because NP-based probes provide a platform for different quencher-fluorophore combinations such as multiple-to-one or multiple-to-multiple pairs, very recently, polymeric and inorganic NP-based activatable probes have been successfully developed. Lee et al. reported an activatable nanoprobe based on a polymer nanoparticle platform [158]. This nanoprobe consists of strongly dual-quenched (dye-dark quencher and dye-dye quenching mechanisms), caspase-3-specific, and NIR fluorogenic peptides on the surface of hyaluronic acid-based, self-assembled polymeric nanoparticles (HA-NPs) that serve as carriers (Figure 11). The activatable nanoprobe can efficiently deliver dual-quenched caspase-3-sensitive fluorogenic peptides into cells, allowing caspase-3-dependent strong fluorescence amplification to be imaged in vitro and in vivo. To date, a large number of similar probes have been reported. However, few probes have been designed to target the caspase cascade during apoptosis. As a proof-of-concept, we described a simple one-step technique that enables real-time imaging of multiple intracellular caspase activities, which involves a straightforward peptide synthesis and a simple mixing step with a commercial transfection agent [159]. The transfection agent efficiently delivered highly quenched fluorogenic probes, comprised of distinctive pairs of dyes and quenchers, to the initiator caspase- 8 and the effector caspase- 3 in apoptotic cells, allowing dual-imaging of the activities of both caspases during the apoptotic process. Furthermore, a set of protease specific substrates of the 
dye were conjugated on the reactive surface of a broad-spectrum nanoquencher, which was generated by incorporating 3-aminopropyltriethoxysilane (APS) conjugated to the individual dark quenchers BHQ-1, BHQ-2, and BHQ-3 (APS-BHQx), as well as the mixture of all three BHQs into mesoporous silica nanoparticles (MSNs) [160]. The nanosensor is capable of producing multiplexed fluorescence signals in the presence of multiple proteases.

Bioluminescence Imaging Probes. Most activatable probes utilize fluorescence as a reporter signal, but bioluminescence imaging (BLI) is another promising modality for optically imaging apoptosis owing to exceptionally high signal-to-noise levels [161, 162]. Based on BLI techniques, many strategies exist for genetically engineered bioluminescent proteins for apoptosis imaging, such as structural changes of substrate-based and BRET-based agents. The common recombinant bioluminescent probes are composed of a "sandwich" linear structure, Luc-DEVD-receptor. However, their molecular size is quite large and the intensity of the luminescence signals is relatively low because of insufficient digestion of the DEVD sequence during apoptosis. To overcome this limitation, Kanno et al. engineered a genetically encoded cyclic luciferase to detect protease activities in living cells and animals [163]. Two fragments of DnaE intein, producing a high yield of cyclic peptide or protein, were fused to neighboring ends of Fluc connected with a substrate sequence for the protease. This cyclic luciferase was demonstrated to quantitatively sense caspase-3 activity in living cells upon extracellular stimuli and to noninvasively image the time-dependent caspase activity in living mice (Figure 12) $[164,165]$. Renilla and firefly luciferases, having substrates of coelenterazine and D-luciferin, respectively, have been used to monitor different bio-

A)

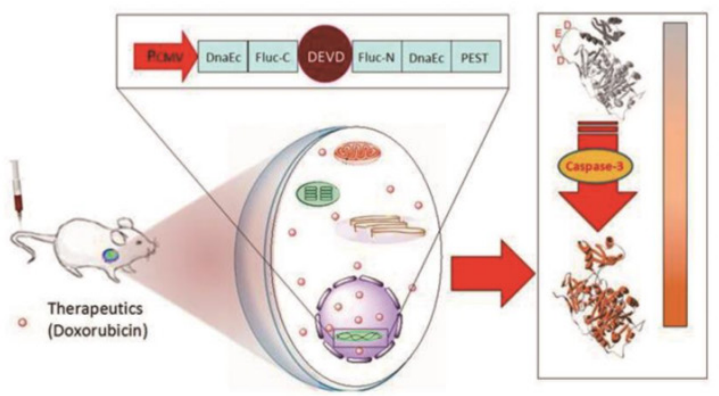

B)

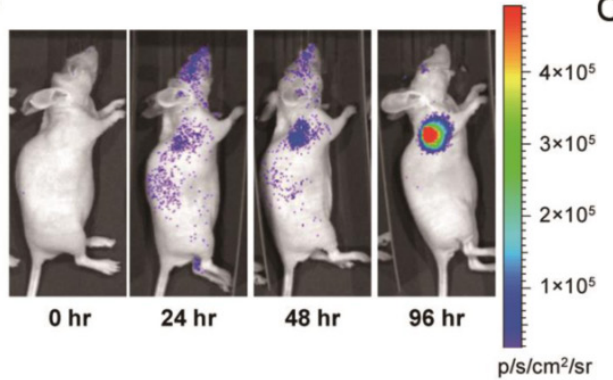

logical processes in a single animal [166]. The ability to image two or more biological processes by using two different luciferases or activatable luciferases, greatly increases the utility of luciferase imaging. Shah et al. utilized dual substrate/reporter bioluminescence imaging (Fluc: Firefly luciferase-luciferin and Rluc: Renilla luciferase-coelenterazine) to test the efficacy of TRAIL using replication-deficient herpes simplex virus (HSV) type 1 amplicon vectors in gliomas. Growth of tumors stably transfected with Fluc $\left(\right.$ Gli36fluc $^{+}$) was readily monitored in vivo by BLI following luciferin administration [167]. HSV amplicon vectors bearing the genes for TRAIL and Rluc injected directly into Gli36fluc+-expressing subcutaneous gliomas revealed peak Rluc activity $36 \mathrm{~h}$ after intratumoral injection as determined by coelenterazine injection followed by imaging. This strategy offers a unique way to monitor both gene delivery and efficacy of TRAIL-induced apoptosis in tumors in vivo in real time by dual enzyme substrate (Rluc/Fluc) imaging. The original BRET system used Rluc as the donor, the derivative of coelenterazine as its substrate and a yellow fluorescent protein (YFP) as the acceptor. In recent years, some GFPs and fluorophores were introduced as acceptor along with luciferin as the donor. Angers et al. first reported the detection of caspase- 3 by the BRET technique in a study of $G$ protein-coupled receptor (GPCR) homodimers at the surface of living cells [168]. The Rluc-DEVD-YFP fusion gene was subcloned from the pT7 plasmid into the mammalian expression vector. The stimulation of caspase- 3 activity by a treatment of the cells with staurosporine promoted a marked decrease in the BRET ratio, indicating that a portion of the fusion protein was cleaved, resulting in the physical separation of the BRET partners. The staurosporine-induced reduction in BRET was blocked by a pretreatment with the caspase- 3 inhibitor, confirming the specificity of the effect.
Figure 12. A genetically encoded cyclic luciferase for the detection of caspase-3 activities. A) Schematic overview of the pcFluc-DEVD system. B) Representative bioluminescent images of 22B-pcFluc-DEVD tumors xenografted mice treated with one dose of doxorubicin $(5 \mathrm{mg} / \mathrm{kg})$. C) Quantification of BLI signal over tumor region. (Adapted from Ref. [165] with permission.) 
MR Imaging Agents. Magnetic resonance imaging (MRI), a highly versatile imaging modality with ultrahigh spatial resolution, has revolutionized clinical diagnostics and has also proven effective in the basic research setting, enabling researchers to spy on the biological process in single cells, organs, or even the living animal models [169]. However, in comparison to other molecular imaging techniques, the principal challenge of MRI lies in its low sensitivity. Contrast agents therefore have been developed to address these limitations. To date, gadolinium chelates and superparamagnetic iron oxide nanoparticles (IONPs) represent the contrast agents most widely used in magnetic resonance imaging [170, 171]. A summary of the recent development of MRI contrast agents used in apoptosis imaging is given.

Magnetic Labeling Strategies Currently, Gd(III) chelates are one of the most commonly used MRI contrast agents in clinical practice. Safety is a significant consideration, and Gd(III) cannot be directly administered in the form of free ions, because of their inherent toxicity due to severe interference with calcium channels and protein binding sites. Therefore, $\mathrm{Gd}(\mathrm{III})$ ions need to be complexed with chelators to minimize toxic side effects. The most commonly used chelating ligands are DTPA, DOTA and their derivatives. In order to conjugate Gd-DOTA and Gd-DTPA to biocompatible macromolecules, various bifunctional chelates of DTPA and DOTA have been developed for conjugation [172]. Bifunctional ligands and small molecular Gd chelates can be readily conjugated to many macromolecules such as proteins, polymers and dendrimers via functional groups such as anhydride, N-hydroxysuccinimide activated carboxylic acid, maleimide, alkynyl and azide. Iron oxide nanoparticles represent the other most commonly used MRI contrast agents. Appropriate physicochemistry and tailored surface properties of iron oxide nanoparticles have been extensively investigated for MR imaging. Surface modification usually confers the needed safety, biocompatibility, stability, hydrophilicity, and the terminal functional groups needed for further conjugation [173]. Surface coating of the nanoparticle can be achieved by using appropriate polymer or surfactants such as poly (ethylene glycol) (PEG), dextran, poly (vinyl alcohol) (PVA), polyethylenimine (PEI), oleic acid (OA), or silane, precious metal. Among different kinds of polymer coating materials, PEG is the most widely used polymer for nanoparticle coating due to its impressive properties such as safety, biocompatibility, stability, and hydrophilicity. In order to attach PEG to nanoparticle, various methods have been established, represented by nanoparticle polymerization and surface silane grafting. In addition, a proper active functional group can provide easy access to nanoparticles for subsequent biological conjugation. Nevertheless, most nanoparticles lack functional groups after the hydrophilic modification. Therefore, an additional surface modification step is required to increase active functional group such as carboxylic acid, amine, maleimide groups. The feasible solution here is connecting with a linker. Till now, many linkers have been designed and applied in the iron oxide nanoparticles based agents, as seen in review [174].

Labelled Gadolinium Complexes. High spin paramagnetic Gd(III) complexes are effective for increasing $T_{1}$ relaxation rate $\left(1 / T_{1}\right)$ and commonly used as $T_{1}$ contrast agents, producing a positive image contrast. However, because of their inherently low sensitivity, large amounts of contrast agents are often required. Strategies employed to deliver sufficient contrast agent to image and amplify the signal in vivo comprise attachment of the contrast agents into lipoproteins, linear polymers, micellar structures, dendrimers and solid lipid nanoparticles (SLNs) [175]. For the detection of exposed PS, biotinylated Annexin V was linked via avidin by covalent binding with Gd-DTPA-labeled biotinylated liposomes [176]. Ex vivo study of cardiovascular apoptosis in the isolated rat heart showed a significant increase in signal intensity of MRI in those regions containing cardiomyocytes at the early stage of apoptosis. Since detection of early apoptotic cell death in intact organs using histology and immunohistochemistry remains challenging, the use of Gd-DTPA-labeled Annexin V in MRI is clearly an improvement in rapid targeting of apoptotic cells in the ischemic and reperfused myocardium. In addition, van Tilborg et al. reported the preparation of paramagnetic liposomes by incorporation of Gd-DTPA-bis(stearylamide) (Gd-DTPA-BSA) lipids within the lipid bilayer of PEGylated liposomes. Multiple human recombinant Annexin V molecules were covalently coupled to introduce specificity for apoptotic cells. The Annexin V-conjugated contrast agents were shown to significantly increase the relaxation rates of apoptotic cell pellets compared to untreated control cells, which suggests that the targeted nanoparticle may have applications for in vivo detection of apoptosis [177]. Recently, the same group developed a small micellar Annexin V-functionalized nanoparticle for noninvasive MR imaging of PS exposing cells in atherosclerotic lesions. In vivo $T_{1}$-weighted MRI of the abdominal aorta in atherosclerotic ApoE-/- mice revealed enhanced uptake of the Annexin V-micelles as compared to control micelles, which corroborated with ex vivo studies (Figure 13) [178]. Binding of the C2A domain of synaptotagmin I to PS expressed on the surface of apoptotic cells, when labeled with gadolinium complexes, can also be 
used to detect the presence of apoptosis using MRI techniques. The preparation of Gd-DTPA-C2A-GST contrast agent by a directly attached method was described [179]. In vivo $T_{1}$-weighted imaging revealed that there was a greater tumor accumulation of the PS-active contrast agent than in control groups.

Peptides and organic molecules with low-molecular weight were also labeled with gadolinium complexes. In a recent work published by Burtea and his co-workers, a hexapeptide (LIKKPF) with high PS binding affinity identified by phage display technology was used to design a targeted MRI contrast agent via labeling the peptide with Gd-DTPA complexes [180]. MR imaging suggested that these complexes were able to visualize cell death in atherosclerotic plaques and in a mouse liver apoptosis model.

Currently, trials to visualize enzyme activity by ${ }^{1} \mathrm{H}$ MRI are in progress. However, one limit of ${ }^{1} \mathrm{H}$ MRI probe for detecting enzyme activity arises from the background signals, which interfere with detection of the probe signals. Thus, some researchers have focused on ${ }^{19} \mathrm{~F}$ MRI, which is sensitive and scarcely shows background signals in animal bodies. Based on these strategies [181], a ${ }^{19} \mathrm{~F}$ MRI probe, Gd-DOTA-DEVD-Tfb consisting mainly of three parts: a $\mathrm{Gd}^{3+}$ complex, an enzyme substrate peptide, and a ${ }^{19} \mathrm{~F}$-containing group $(\mathrm{Tfb})$, was synthesized for detecting caspase-3 activity (Figure 14) [182]. When Gd-DOTA-DEVD-Tfb was treated with caspase-3, the ${ }^{19} \mathrm{~F}$ NMR peak became sharper and higher in a time-dependent manner, which indicated the intra-molecular paramagnetic effect from $\mathrm{Gd}^{3+}$ to ${ }^{19} \mathrm{~F}$ was cancelled by the cleavage of the probe. In this fashion, the same group chose 7-amino-4trifluoromethylcoumarin (AFC) as a reporter group that is active in both ${ }^{19} \mathrm{~F}$ MRI and fluorescence measurement to construct Gd-DOTA-DEVD-AFC [183]. After the enzyme cleavage, the ${ }^{19} \mathrm{~F}$ MRI signal is increased in much the same manner as in the case of Gd-DOTA-DEVD-Tfb. The search for physiologically responsive diagnostic agents is an important driving force in the current development of contrast agents for MRI. Paramagnetic chemical exchange saturation transfer (PARACEST) agents hold promise as sensors for measuring various parameters of their biological environment. In this perspective, Yoo et al. developed a "smart" PARACEST MRI contrast agent, DEVD-(Tm-DOTA) amide that can detect an active caspase-3 enzyme [184]. Studies with DEVD-(Tm-DOTA) amide showed PARACEST with good sensitivity (as low as 5-50 $\mathrm{nM}$ ) at physiological $\mathrm{pH}$ and temperature, indicating that this MRI contrast agent may be useful for in vivo molecular imaging.
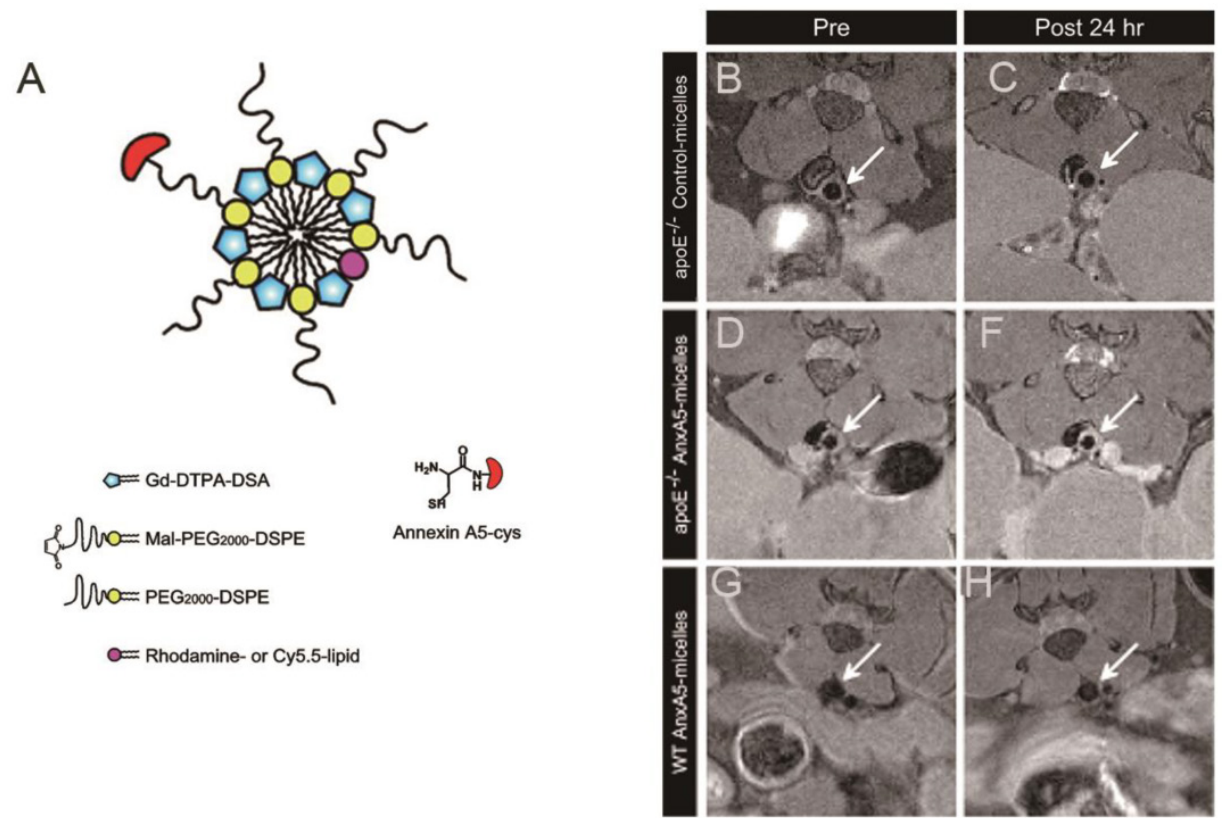

Figure 13. Schematic of annexin A5-micelles nanoparticle (A) and Tl-weighted in vivo MR images at the level of the abdominal aorta (arrow). Scans were made before (left panel) and $24 \mathrm{~h}$ after (right panel) contrast agent injection. ApoE-/- mice received either control-micelles (B, C) or annexin A5-micelles (E, F). Wild-type (WT) C57BL/6 mice only received annexin A5-micelles (G, H). (Adapted from Ref. [178] with permission.) 


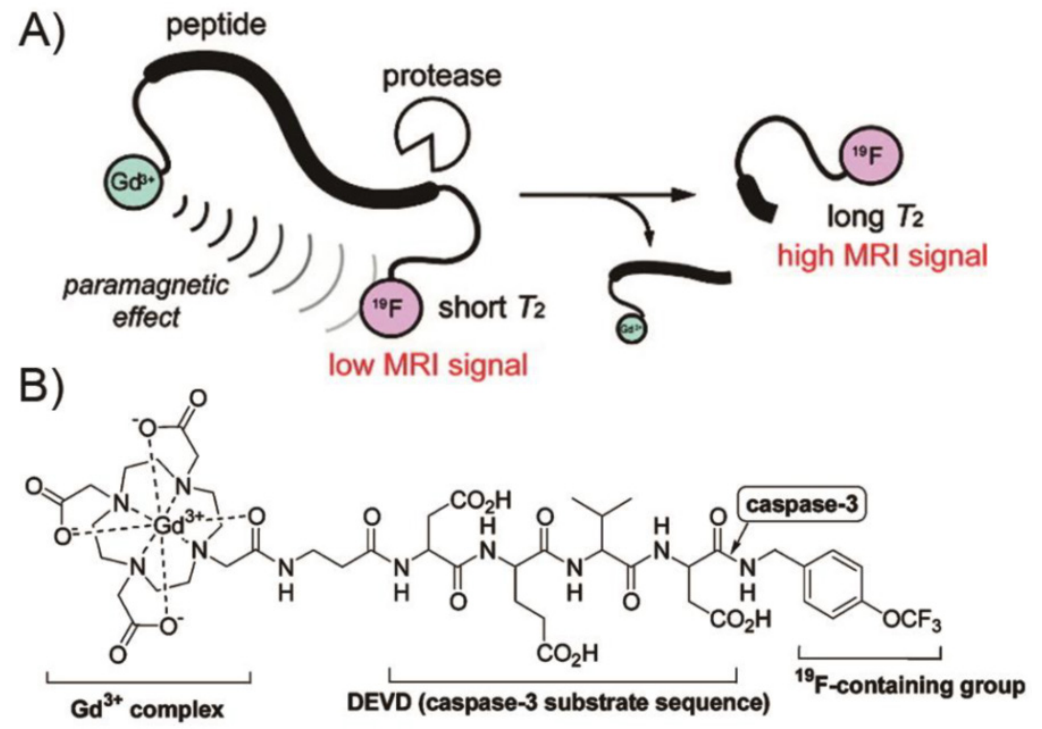

Figure 14. A) Design principle of ${ }^{19} \mathrm{~F}-M R I$ probe detecting protease activity. B) Structure of Gd-DOTA-DEVD-Tfb. (Adapted from Ref. [182] with permission.)

Labelled Iron Oxide Nanoparticles. Superparamagnetic iron oxide nanoparticles are the most representative $T_{2}$ contrast agents, which are effective in enhancing $T_{2}$ relaxation rate $\left(1 / T_{2}\right)$, generating negative image contrast. In recent years, considerable efforts have been spent in the development of this kind of nanoparticles [185]. A highly stabilized and cross-linked derivative of monodisperse iron oxide (MION), known as cross-linked iron oxide (CLIO), was developed for molecular imaging applications [186]. Annexin V-CLIO, which had an average of 2.7 Annexin $\mathrm{V}$ proteins linked through disulfide bonds per CLIO nanoparticle appears to be an effective MR imaging probe for detecting apoptosis [187]. Moreover, one of the recent studies in this field published by van Tilborg et al. is devoted to the internalization of Annexin V-functionalized iron oxide particles [188]. This process is considered to be driven by the formation of two-dimensional crystals of Annexin V trimers on the apoptotic cell membrane [189].

As an alternative to using Annexin V, the C2A domain was subsequently conjugated to superparamagnetic iron oxide (SPIO) nanoparticles [190]. Detection of apoptotic cells, using this contrast agent, was demonstrated both in vitro, with isolated apoptotic tumor cells, and in vivo, in a tumor treated with chemotherapeutic drugs. In order to increase probe sensitivity and circumvent possible in vivo toxicities of gadolinium chelates, Burtea et al. screened an M13 phage display library on PS-coated enzyme-linked immunosorbent assay (ELISA) plates and identified another PS binding hexapeptide (TLVSSL), which was then attached to ultrasmall superparamagnetic iron oxide particles (USPIO), producing a new MRI contrast agent [191]. In vivo MRI performed in different apoptosis models showed that peptide-USPIO particles were able to detect increased apoptosis [192,193].

Multimodal Imaging Probes. Commonly used imaging modalities in the clinic including optical imaging, MRI, CT, ultrasound (US), and PET or SPECT, have capabilities varying from anatomical to functional imaging. Each imaging modality has intrinsic limitations, such as relatively low sensitivity or spatial resolution, and thus it is difficult to acquire accurate and reliable biological information by a single imaging modality [194]. To compensate for this problem, combinations of imaging modalities have gained popularity, allowing integration of the advantages of individual modalities, while reducing their limitations. Such hybrid systems might allow simultaneous and/or sequential acquisitions with different modalities, accomplishing high sensitivity and high resolution and providing more detailed anatomical and biological information.

Since the first fused PET/CT instrument reported by Townsend et al. in 1998, several kinds of high-resolution dual- or tri-modality systems such as SPECT/CT, SPECT/optical, PET/optical, PET/SPECT/CT, and PET/MRI have been developed. However, simultaneous measurements by different modalities can't be accomplished unless the multimodal imaging probes have identical pharmacokinetic properties. The development of multimodal imaging probes is far from trivial for a pharmaceutical chemist. In the next section, we will provide an overview of the many strategies that have been used to create multimodal probes and to apply them in imaging of apoptosis.

Multimodal Labeling Strategies. In the design of multimodal imaging probes, it is of less value if the 
different modalities offer similar, rather than complementary strengths. This is why the highly sensitive imaging modalities such as PET and optical imaging are frequently combined with other imaging modalities with high spatial resolution (MR, CT, etc.). Owing to the high loading capacity of payloads and the intrinsic properties such as magnetism or luminescence, nanoparticles (NPs) have been the favorable platforms to combine different modalities of moieties for multimodal imaging. Compared with the complex organic synthesis of small molecule multimodal probes, it is simple and relatively facile for making NP-based multimodal probes, allowing change of moieties of NPs without necessitating redesign of the overall synthetic protocol. Generally, these NPs such as IONPs, have been coated with biocompatible polymers, such as dextran, PEG, or their derivatives to provide surface functionalization. These surface functionalities can also bind different imaging or therapeutic moieties to NPs platforms via conjugates, core/shell structure or doping. These strategies applied to the design of multimodal probes have been described in detail in several excellent reviews [195-197]. Small molecule multimodal probes are simpler in structure than NP-based multimodal probes, but perhaps more complex to synthesize. Modification to small molecule multimodal probes must not affect their biological activity. Thus, the chemistry used in the conjugation of moieties to molecules must be compatible and mild. Secondly, in order to combine two or more imaging modalities directly, some spacers (or linkers) are needed to minimize interference of bonds and to maintain molecule function. In addition, minimizing the number of alteration points of the molecule (often 1:1 ratio), while attaching diverse moieties, may help maintain bioactivity of small molecules. In short, strategies are needed to preserve the small size and the pharmacokinetic properties of the parent probes.

Nanoparticles-Based Multimodal Probes. During the past decades, many multimodal imaging probes targeting apoptosis have been developed [198]. Schellenberger et al. described the synthesis of a magneto/optical form of Annexin V, Anx-CLIO-Cy5.5, achieved by reacting SATAylated Annexin V with an SPDP activated fluorescent CLIO nanoparticle [199]. The conjugation strategy preserved the strength of the interaction between Annexin V and apoptotic cells in vitro and in vivo, and was readily detectable by standard MR imaging or NIRF optical methods [200]. van Tilborg et al. developed a Annexin V-conjugated bimodal nanoparticle composed of a quantum dot encapsulated in a paramagnetic micelle prepared with Gd-lipids and fluorescein containing lipids as well as additional PEGylated lipids, making it suitable for both optical imaging and MRI [201]. The specificity of the Annexin V-conjugated nanoparticles for apoptotic cells was demonstrated both with fluorescence microscopy and MRI, confirming its potential for the detection of apoptosis with both imaging modalities in vivo [202]. Recently, Zhang et al. described and evaluated Annexin V conjugated, polyethylene glycol-coated, core-cross-linked polymeric micelles (CCPMs) dually labeled with NIR fluorophores and a radioisotope (111In) [203]. Annexin V-CCPM allowed visualization of tumor apoptosis by both nuclear and optical techniques in vitro and in vivo. Later, micro single-photon emission tomography/computed tomography ( $\mu \mathrm{SPECT} / \mathrm{CT})$ and fluorescence molecular tomography (FMT) were employed to evaluate Annexin V-CCPMs in various disease models [204]. The study indicated that dually labeled Annexin $\mathrm{V}$-CCPMs has the potential to aid the diagnosis of disease states or tissue responses involving abnormal cell death. Zhang et al. have described and fully characterized a liposomal nanoprobe, PGN-L-IO/DiR, based on a human a monoclonal antibody, PGN635 that specifically targets PS [205]. In that study, SPIO were packed into the core of liposomes, while near-infrared dye, DiR was incorporated into the lipophilic bilayer. In vitro and in vivo longitudinal MRI and optical imaging were performed and the results indicated that PS-targeted liposomes may provide a useful platform for tumor-targeted delivery of imaging agents or potentially anti-cancer drugs for cancer therapy. All the same, multimodality imaging of apoptosis using nanoparticles is still in its infancy. Future designs that are more clinically relevant would be beneficial. Multifunctional NPs that recognize other apoptosis targets (not PS) would also be important and need further development.

Small Molecule Multimodal Probes. Small molecules labeled with different kinds of reporter moieties can be used for multimodal imaging. Lee et al. reported an optical-nuclear dual mode molecular probe with complementary reporting strategies to image the molecular events of caspase-3 activation [206]. Molecular probe LS498 consists of DOTA for chelating a radionuclide ${ }^{64} \mathrm{Cu}$, a NIR fluorophore-quencher pair and caspase- 3 specific peptide substrate. In vitro and in vivo studies demonstrated the feasibility of using radionuclide imaging for localizing and quantifying the distribution of the molecular probes and of optical imaging for reporting the functional status of diagnostic enzymes. However, the relative paucity of tags may limit probe utility to modalities of similar sensitivities [196], nevertheless, the potential for rapid diffusion through tissue may be attractive for in vivo applications. 
Table 3. Some of Radiolabeled Apoptosis Imaging Agents in Preclinical and Clinical Trials.

\begin{tabular}{|c|c|c|c|c|c|}
\hline Radiotracers & Class & Status & Investigators & Disease Group & Ref. \\
\hline 99mTc-HYNIC-Annexin V & Protein & Phase II/III & Theseus Imaging Corp. & NSCLC & 75,76 \\
\hline 99mTc-BTAP-Annexin V & Protein & Phase I & Theseus Imaging Corp. & Healthy Volunteers & 67 \\
\hline${ }^{18} \mathrm{~F}-\mathrm{CP} 18$ & Peptide & Phase II & Kurdziel et al. & $\begin{array}{l}\text { Ovarian Neoplasms, } \\
\text { Fallopian Tube } \\
\text { Neoplasms }\end{array}$ & 99 \\
\hline${ }^{18} \mathrm{~F}-\mathrm{ICMT}-11$ & Isatin family & Phase I & QuIC-ConCePT Consortium & Healthy Volunteers & 133 \\
\hline${ }^{18} \mathrm{~F}-\mathrm{ML}-10$ & Aposense family & Phase I/II & NST NeuroSurvival Technologies Ltd. & $\begin{array}{l}\text { Acute Ischemic Cerebral Stroke, } \\
\text { Metastatic Brain Tumors }\end{array}$ & 114,215 \\
\hline
\end{tabular}

\section{Clinical Translation of Apoptosis Im- aging Agents}

Since 1972, when Kerr et al. first coined the term apoptosis, intense attempts to explore the rich diversity of biology and chemistry of apoptosis have created a "pipeline" of exciting new apoptosis imaging probes. Based on various biochemical events during the apoptosis, numerous tracers have been developed for non-invasive detection of this process [207-211]. Table 3 summarizes some of the radiotracers that have been advanced to early or late clinical studies. The imaging of apoptosis has witnessed a dynamic evolution over the past decades from the initial proof-of-concept studies using PS-targeted, protein-based probes represented by Annexin V to approaches based on small molecule structures specific for apoptosis. Despite the potential of many probes tested in preclinical animal models, there are limited clinical examples of the use of SPECT or PET for imaging of apoptosis. This may be attributable to the complex set of features required of a probe for imaging apoptosis in clinical practice. Overall, a desirable apoptosis imaging probe with clinical translation potential is expected to have the following unique characteristics: 1) high selectivity and specificity for apoptotic cells; 2 ) high stability in vitro and in vivo; 3 ) favorable pharmacokinetics; 4) compatibility with imaging equipment, labeling techniques, and mathematic algorithms for quantitative analysis of the signal; 5) low immunogenicity and toxicity; and 6) feasibility of economical production $[207,212]$. In addition, due to the time-dependent nature of apoptosis, a high-contrast image must be achieved within a specific time window. Since apoptosis imaging probes constitute a subtype of pharmaceuticals, the drug and probe discovery thus share lots of similarities. Scientists can apply the knowledge and experience gained from the drug discovery process to facilitate molecular probe discovery. The general workflow for exploratory investigational new drug (eIND) approaches can also represent the streamline for a probe development, allowing expedited translation of some promising SPECT or PET imaging probes into the clinic [213]. Since Feridex has been out of market, it is unlikely that any iron oxide based imaging probes including targeted iron oxide probes will be approved by the Food and Drug Administration (FDA) in the near future. Fortunately and conveniently, due to their close gyromagnetic ratio $(\gamma)$ values, the signal of ${ }^{19} \mathrm{~F}-\mathrm{MRI}$ probes can be detected with most ${ }^{1} \mathrm{H}-\mathrm{NMR}$ instruments by appropriately tuning the radio-frequency coils. Accordingly, the development of ${ }^{19} \mathrm{~F}-\mathrm{MRI}$ probes may represent the future direction of MRI agents used in clinical settings. Optical imaging is at the initial stage of clinical testing in fields such as surgical navigation [214]. As the fluorescent dye indocyanine green (ICG) translates from preclinical studies to patients, potential applications of fluorescent molecular imaging in clinical medicine are expected to expand dramatically. A number of optical probes with potential as markers of apoptosis are in the preclinical stage, but they are likely still a long way from FDA approval. At present, there are no multimodal probes approved by FDA. This partly accounts for the lack of hybrid instruments for clinical practice except for PET/CT and SPECT/CT. However, multimodality imaging is thriving and still evolving rapidly. Multimodal imaging probes, highly complementary to the hybrid imaging systems are being developed and are likely to flourish.

\section{Conclusions and Perspectives}

Over the years, a number of methods have been developed to detect apoptosis. There are several microscopic techniques such as optical microscopy, the TUNEL assay and flow cytometry [216]. These conventional apoptosis detection methods are complementary to noninvasive imaging techniques and provide critical standards to confirm the specificity of the apoptotic signal provided by various preclinical and clinical imaging methods. Research in the past decades has produced a wealth of macroscopic imaging methods, in various stages of development, based on use of nanoparticles, proteins, peptides and small organic molecules. The potential of these probes for 
effective imaging of apoptosis in vivo could benefit many areas of clinical medicine. Nevertheless, the current enthusiasm for clinical applications has been dampened by the inherent difficulties of developing clinical imaging agents and by the recognition that no agent has cleared the obstacles and reached the market to date.

Can the challenges associated with successful development of clinical imaging agents be overcome? The answer is YES. Advancements have numerous biochemical features of apoptosis that can serve as targets for imaging probes, as well as facilitate chemical design strategies, biological evaluation and improved translational research, which are all crucial to the success of clinical imaging agents that may outperform existing ones. Furthermore, with the advent of theranostics [217-221], the combination of apoptosis imaging strategies with therapy provides researchers and physicians with extraordinary insight into apoptosis and thus enlarges the armory for the fight against a range of diseases [222,223]. Consequently, it is our genuine belief that there is convincing that one or more of these probes will clear the multiple hurdles of the drug development pathway to become clinically useful imaging agents in the not too distant future.

\section{Acknowledgements}

We acknowledge the financial support from The National Natural Science Foundation of China (No.30900377 and 81271634), Doctoral Fund of Ministry of Education of China (No. 20120162110070), Hunan Provincial Natural Science Foundation of China (12JJ1012), and the Intramural Research Program, National Institute of Biomedical Imaging and Bioengineering, National Institutes of Health.

\section{Competing Interests}

The authors have declared that no competing interest exists.

\section{References}

1. Kerr JF, Wyllie AH, Currie AR. Apoptosis: a basic biological phenomenon with wide-ranging implications in tissue kinetics. Br J Cancer. 1972; 26: 239-57.

2. Green DR, Kroemer G. The pathophysiology of mitochondrial cell death. Science. 2004; 305: 626-9.

3. Levine B, Kroemer G. Autophagy in the pathogenesis of disease. Cell. 2008; 132: 27-42.

4. Bao $\mathrm{S}$, Wu $\mathrm{Q}$, McLendon RE, Hao $\mathrm{Y}$, Shi $\mathrm{Q}$, Hjelmeland $\mathrm{AB}$, et al. Glioma stem cells promote radioresistance by preferential activation of the DNA damage response. Nature. 2006; 444: 756-60.

5. Starkey JR, Rebane AK, Drobizhev MA, Meng F, Gong A, Elliott A, et al. New two-photon activated photodynamic therapy sensitizers induce xenograft tumor regressions after near-IR laser treatment through the body of the host mouse. Clin Cancer Res. 2008; 14: 6564-73.

6. Zhang L, Ren X, Alt E, Bai X, Huang S, Xu Z, et al. Chemoprevention of colorectal cancer by targeting APC-deficient cells for apoptosis. Nature. 2010; 464: 1058-61.

7. Ashkenazi A, Dixit VM. Death receptors: signaling and modulation. Science. 1998; 281: 1305-8.

8. Hengartner MO. The biochemistry of apoptosis. Nature. 2000; 407: 770-6
9. Ron D, Walter P. Signal integration in the endoplasmic reticulum unfolded protein response. Nat Rev Mol Cell Biol. 2007; 8: 519-29.

10. Tabas I, Ron D. Integrating the mechanisms of apoptosis induced by endoplasmic reticulum stress. Nat Cell Biol. 2011; 13: 184-90.

11. Leist $M$, Jäättelä $M$. Four deaths and a funeral: from caspases to alternative mechanisms. Nat Rev Mol Cell Biol. 2001; 2: 589-98.

12. Schlegel RA, Williamson P. Phosphatidylserine, a death knell. Cell Death Differ. 2001; 8: 551-63.

13. Han J, Zhong C, Zhang D. Programmed necrosis: backup to and competitor with apoptosis in the immune system. Nat Immunol. 2011; 12: 1143-9.

14. Liu P, Xu B, Shen $\mathrm{W}, \mathrm{Zhu} \mathrm{H}, \mathrm{Wu} \mathrm{W}, \mathrm{Fu} \mathrm{Y}$, et al. Dysregulation of TNFa-induced necroptotic signaling in chronic lymphocytic leukemia: suppression of CYLD gene by LEF1. Leukemia. 2012; 26: 1293-300.

15. Weissleder R. Molecular imaging: exploring the next frontier. Radiology. 1999; 212: 609-14

16. Gerke V, Moss SE. Annexins: from structure to function. Physiol Rev. 2002; 82: 331-71.

17. Oling F, Bergsma-Schutter W, Brisson A. Trimers, dimers of trimers, and trimers of trimers are common building blocks of annexin a5 two-dimensional crystals. J Struct Biol. 2001; 133: 55-63.

18. van den Eijnde SM, Luijsterburg AJ, Boshart L, De Zeeuw CI, van Dierendonck $\mathrm{JH}$, Reutelingsperger $\mathrm{CP}$, et al. In situ detection of apoptosis during embryogenesis with annexin V: from whole mount to ultrastructure. Cytometry. 1997; 29: 313-20.

19. van den Eijnde SM, Boshart L, Reutelingsperger CP, Zeeuw CI, Vermeij-Keers C. Phosphatidylserine plasma membrane asymmetry in vivo: a pancellular phenomenon which alters during apoptosis. Cell Death Differ. 1997; 4: 311-6.

20. Kim YE, Chen J, Chan JR, Langen R. Engineering a polarity-sensitive biosensor for time-lapse imaging of apoptotic processes and degeneration. Nat Methods. 2010; 7: 67-73

21. Kim YE, Chen J, Langen $R$, Chan JR, Monitoring apoptosis and neuronal degeneration by real-time detection of phosphatidylserine externalization using a polarity-sensitive indicator of viability and apoptosis. Nat Protoc. 2010; 5: 1396-405.

22. Krajewska M, You Z, Rong J, Kress C, Huang X, Yang J, et al. Neuronal deletion of caspase 8 protects against brain injury in mouse models of controlled cortical impact and kainic acid-induced excitotoxicity. PLoS One. 2011; 6: 24341.

23. Bleackley RC, Heibein JA. Enzymatic control of apoptosis. Nat Prod Rep. 2001; 18: 431-40.

24. Cen H, Mao F, Aronchik I, Fuentes RJ, Firestone GL. DEVD-NucView488: a novel class of enzyme substrates for real-time detection of caspase- 3 activity in live cells. FASEB J. 2008; 22: 2243-52.

25. Green DR, Reed JC. Mitochondria and apoptosis. Science. 1998; 281: 1309-12.

26. Cossarizza A, Baccarani-Contri M, Kalashnikova G, Franceschi C. A new method for the cytofluorimetric analysis of mitochondrial membrane potential using the J-aggregate forming lipophilic cation 5,5',6,6'-tetrachloro-1,1',3,3'-tetraethylbenzimidazolcarbocyanine iodide (JC-1). Biochem Biophys Res Commun. 1993; 197: 40-5.

27. Salvioli S, Ardizzoni A, Franceschi C, Cossarizza A. JC-1, but not DiOC6(3) or rhodamine 123 , is a reliable fluorescent probe to assess delta psi changes in intact cells: implications for studies on mitochondrial functionality during apoptosis. FEBS Lett. 1997; 411: 77-82.

28. Smiley ST, Reers M, Mottola-Hartshorn C, Lin M, Chen A, Smith TW, et al. Intracellular heterogeneity in mitochondrial membrane potentials revealed by a J-aggregate-forming lipophilic cation JC-1. Proc Natl Acad Sci U S A. 1991; 88: $3671-5$

29. Bouchier-Hayes L, Muñoz-Pinedo C, Connell S, Green DR. Measuring apoptosis at the single cell level. Methods. 2008; 44: 222-8.

30. Bortner CD, Oldenburg NB, Cidlowski JA. The role of DNA fragmentation in apoptosis. Trends Cell Biol. 1995; 5: 21-6.

31. Collins JA, Schandi CA, Young KK, Vesely J, Willingham MC. Major DNA fragmentation is a late event in apoptosis. J Histochem Cytochem. 1997; 45: 923-34.

32. Gorczyca W, Gong J, Darzynkiewicz Z. Detection of DNA strand breaks in individual apoptotic cells by the in situ terminal deoxynucleotidyl transferase and nick translation assays. Cancer Res. 1993; 53: 1945-51.

33. Negoescu A, Guillermet C, Lorimier P, Brambilla E, Labat-Moleur F. Importance of DNA fragmentation in apoptosis with regard to TUNEL specificity. Biomed Pharmacother. 1998; 52: 252-8.

34. Meldal M, Tornøe CW. Cu-catalyzed azide-alkyne cycloaddition. Chem Rev. 2008; 108: 2952-3015.

35. Salic A, Mitchison TJ. A chemical method for fast and sensitive detection of DNA synthesis in vivo. Proc Natl Acad Sci U S A. 2008; 105: 2415-20.

36. Smith G, Nguyen QD, Aboagye EO. Translational imaging of apoptosis. Anticancer Agents Med Chem. 2009; 9: 958-67.

37. Damianovich M, Ziv I, Heyman SN, Rosen S, Shina A, Kidron D, et al. ApoSense: a novel technology for functional molecular imaging of cell death in models of acute renal tubular necrosis. Eur J Nucl Med Mol Imaging. 2006; 33: 281-91.

38. Watanabe M, Hitomi M, van der Wee K, Rothenberg F, Fisher SA, Zucker R, et al. The pros and cons of apoptosis assays for use in the study of cells, tissues, and organs. Microsc Microanal. 2002; 8: 375-91.

39. Hakumäki JM, Liimatainen T. Molecular imaging of apoptosis in cancer. Eur J Radiol. 2005; 56: 143-53. 
40. Sugiura G, Kühn H, Sauter M, Haberkorn U, Mier W. Radiolabeling strategies for tumor-targeting proteinaceous drugs. Molecules. 2014; 19: 2135-65.

41. Lahorte CM, Vanderheyden JL, Steinmetz N, van de Wiele C, Dierckx RA, Slegers G. Apoptosis-detecting radioligands: current state of the art and future perspectives. Eur J Nucl Med Mol Imaging. 2004; 31: 887-919.

42. Lee S, Xie J, Chen X. Peptides and peptide hormones for molecular imaging and disease diagnosis. Chem Rev. 2010; 110: 3087-111.

43. Blankenberg FG, Katsikis PD, Tait JF, Davis RE, Naumovski L, Ohtsuki K, et al. In vivo detection and imaging of phosphatidylserine expression during programmed cell death. Proc Natl Acad Sci U S A. 1998; 95: 6349-54.

44. Stratton JR, Dewhurst TA, Kasina S, Reno JM, Cerqueira MD, Baskin DG, et al. Selective uptake of radiolabeled annexin $\mathrm{V}$ on acute porcine left atrial thrombi. Circulation. 1995; 92: 3113-21.

45. Fonge H, de Saint Hubert M, Vunckx K, Rattat D, Nuyts J, Bormans G, et al. Preliminary in vivo evaluation of a novel ${ }^{99 \mathrm{~m} T c-l a b e l e d ~ H Y N I C-c y s-a n n e x i n ~ A 5 ~}$ as an apoptosis imaging agent. Bioorg Med Chem Lett. 2008; 18: 3794-8.

46. Vanderheyden JL, Liu G, He J, Patel B, Tait JF, Hnatowich DJ. Evaluation of 99mTc-MAG3-annexin A5: influence of the chelate on in vitro and in vivo properties in mice. Nucl Med Biol. 2006; 33: 135-44.

47. Yang DJ, Azhdarinia A, Wu P, Yu DF, Tansey W, Kalimi SK, et al. In vivo and in vitro measurement of apoptosis in breast cancer cells using 99mTc-EC-annexin V. Cancer Biother Radiopharm. 2001; 16: 73-83.

48. Tait JF, Brown DS, Gibson DF, Blankenberg FG, Strauss HW. Development and characterization of annexin $\mathrm{V}$ mutants with endogenous chelation sites for 99mTc. Bioconjug Chem. 2000; 11: 918-25.

49. Tait JF, Smith C, Gibson DF. Development of annexin V mutants suitable for labeling with Tc(I)-carbonyl complex. Bioconjug Chem. 2002; 13: 1119-23.

50. Wen X, Wu QP, Ke S, Wallace S, Charnsangavej C, Huang P, et al. Improved radiolabeling of PEGylated protein: PEGylated annexin $\mathrm{V}$ for noninvasive imaging of tumor apoptosis. Cancer Biother Radiopharm. 2003; 18: 819-27.

51. Ke S, Wen X, Wu QP, Wallace S, Charnsangavej C, Stachowiak AM, et al. Imaging taxane-induced tumor apoptosis using PEGylated, ${ }^{111}$ In-labeled annexin V. J Nucl Med 2004; 45: 108-15.

52. Smith-Jones PM, Afroze A, Zanzonico P, Tait J, Larson SM, Strauss HW. ${ }^{68} \mathrm{Ga}$ labelling of annexin-V: comparison to ${ }^{99 \mathrm{~m} T c-a n n e x i n-V}$ and ${ }^{67} \mathrm{Ga}-A n n e x i n . ~ J$ Nucl Med. 2003; 44(Suppl 1): S49-S50.

53. Wängler C, Wängler B, Lehner S, Elsner A, Todica A, Bartenstein P, et al. A universally applicable ${ }^{6} \mathrm{Ga}$-labeling technique for proteins. J Nucl Med. 2011; 52: 586-91.

54. Li X, Link JM, Stekhova S, Yagle KJ, Smith C, Krohn KA, et al. Site-specific labeling of annexin V with F-18 for apoptosis imaging. Bioconjug Chem. 2008; 19: $1684-8$

55. Dekker B, Keen H, Lyons S, Disley L, Hastings D, Reader A, et al. MBP-annexin A5 radiolabelled directly with iodine-124 can be used to image apoptosis in vivo using PET. Nucl Med Biol. 2005; 32: 241-52.

56. Cauchon N, Langlois R, Rousseau JA, Tessier G, Cadorette J, Lecomte R, et al. PET imaging of apoptosis with ${ }^{64} \mathrm{Cu}$-labeled streptavidin following pretargeting of phosphatidylserine with biotinylated annexin-V. Eur J Nucl Med Mol Imaging. 2007; 34: 247-58.

57. Cheng Q, Lu L, Grafström J, Olofsson MH, Thorell JO, Samén E, et al. Combining [ $\left.{ }^{11} \mathrm{C}\right]-A n x A 5$ PET imaging with serum biomarkers for improved detection in live mice of modest cell death in human solid tumor xenografts. PLoS One. 2012; 7: 42151.

58. Cheng Q, Lu L, Grafström J, Olofsson MH, Thorell JO, Samén E, et al. Site-specifically ${ }^{11} \mathrm{C}$-labeled Sel-tagged annexin A5 and a size-matched control for dynamic in vivo PET imaging of protein distribution in tissues prior to and after induced cell death. Biochim Biophys Acta. 2013; 1830: 2562-73.

59. Wang F, Fang W, Zhang MR, Zhao M, Liu B, Wang Z, et al. Evaluation of chemotherapy response in VX2 rabbit lung cancer with ${ }^{18} \mathrm{~F}-$ labeled $\mathrm{C} 2 \mathrm{~A}$ domain of synaptotagmin I. J Nucl Med. 2011; 52: 592-9.

60. Zhao M, Zhu X, Ji S, Zhou J, Ozker KS, Fang W, et al. 99mTc-labeled C2A domain of synaptotagmin I as a target-specific molecular probe for noninvasive imaging of acute myocardial infarction. J Nucl Med. 2006; 47: 1367-74.

61. Waehrens LN, Rasmussen JT, Heegaard CW, Falborg L. Preparation and in vitro evaluation of $99 \mathrm{mTc}$-labelled bovine lactadherin as a novel radioligand for apoptosis detection. J Label Compd Radiopharm. 2007; 50: 211-17.

62. Lahorte CM, Vanderheyden JL, Steinmetz N, van de Wiele C, Dierckx RA, Slegers G. Apoptosis-detecting radioligands: current state of the art and future perspectives. Eur J Nucl Med Mol Imaging. 2004; 31: 887-919.

63. Boersma HH, Kietselaer BL, Stolk LM, Bennaghmouch A, Hofstra L, Narula J, et al. Past, present, and future of annexin A5: from protein discovery to clinical applications. J Nucl Med. 2005; 46: 2035-50.

64. Vangestel C, Peeters M, Mees G, Oltenfreiter R, Boersma HH, Elsinga PH, et al. In vivo imaging of apoptosis in oncology: an update. Mol Imaging. 2011; 10: 340-58.

65. Kemerink GJ, Boersma HH, Thimister PW, Hofstra L, Liem IH, Pakbiers MT, et al. Biodistribution and dosimetry of ${ }^{99 m T c-B T A P-a n n e x i n-V}$ in humans. Eur J Nucl Med. 2001; 28: 1373-8.

66. Narula J, Acio ER, Narula N, Samuels LE, Fyfe B, Wood D, et al. Annexin-V imaging for noninvasive detection of cardiac allograft rejection. Nat Med. 2001; 7: 1347-52

67. Hofstra L, Dumont EA, Thimister PW, Heidendal GA, DeBruine AP, Elenbaas TW, et al. In vivo detection of apoptosis in an intracardiac tumor. J Am Med Assoc. 2001; 285: 1841-2.
68. Kown MH, Strauss HW, Blankenberg FG, Berry GJ, Stafford-Cecil S, Tait JF, et al. In vivo imaging of acute cardiac rejection in human patients using 99mtechnetium labeled annexin V. Am J Transplant. 2001; 1: 270-7.

69. Abrams MJ, Juweid M, tenKate CI, Schwartz DA, Hauser MM, Gaul FE, et al. Technetium-99m-human polyclonal IgG radiolabeled via the hydrazino nicotinamide derivative for imaging focal sites of infection in rats. J Nucl Med. 1990; 31: 2022-8.

70. Kown MH, van der Steenhoven TJ, Jahncke CL, Mari C, Lijkwan MA, Koransky ML, et al. Zinc chloride-mediated reduction of apoptosis as an adjunct immunosuppressive modality in cardiac transplantation. J Heart Lung Transplant. 2002; 21: 360-5.

71. Belhocine T, Steinmetz N, Hustinx R, Bartsch P, Jerusalem G, Seidel L, et al. Increased uptake of the apoptosis-imaging agent ${ }^{99 \mathrm{~m} T c}$ recombinant human Annexin $\mathrm{V}$ in human tumors after one course of chemotherapy as a predictor of tumor response and patient prognosis. Clin Cancer Res. 2002; 8: 2766-74.

72. Kemerink GJ, Liu X, Kieffer D, Ceyssens S, Mortelmans L, Verbruggen AM, et al. Safety, biodistribution, and dosimetry of 99mTc-HYNIC-annexin V, a novel human recombinant annexin V for human application. J Nucl Med. 2003; 44: 947-52.

73. Hoebers FJ, Kartachova M, de Bois J, van den Brekel MW, van Tinteren H, van

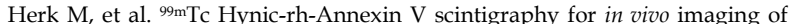
apoptosis in patients with head and neck cancer treated with chemoradiotherapy. Eur J Nucl Med Mol Imaging. 2008; 35: 509-18.

74. Rottey S, van den Bossche B, Slegers G, Van Belle S, van de Wiele C. Influence of chemotherapy on the biodistribution of [99mTc] hydrazinonicotinamide annexin V in cancer patients. Q J Nucl Med Mol Imaging. 2009; 53: 127-32.

75. Kartachova M, van Zandwijk N, Burgers S, van Tinteren H, Verheij M, Valdés Olmos RA. Prognostic significance of 99mTc Hynic-rh-annexin V scintigraphy during platinum-based chemotherapy in advanced lung cancer. J Clin Oncol. 2007; 25: 2534-9.

76. Kartachova MS, Valdés Olmos RA, Haas RL, Hoebers FJ, Herk M, Verheij M. 99mTc-HYNIC-rh-annexin-V scintigraphy: visual and quantitative evaluation of early treatment-induced apoptosis to predict treatment outcome. Nucl Med Commun. 2008; 29: 39-44.

77. Lu C, Jiang Q, Hu M, Tan C, Ji Y, Yu H, et al. Preliminary biological evaluation of novel $99 \mathrm{mTc}$-Cys-annexin A5 as a apoptosis imaging agent. Molecules. 2013; 18: 6908-18.

78. Benali K, Louedec L, Azzouna RB, Merceron O, Nassar P, Al Shoukr F, et al. Preclinical validation of ${ }^{99 \mathrm{mTc}-a n n e x i n ~ A 5-128}$ in experimental autoimmune myocarditis and infective endocarditis: comparison with 99mTc-HYNIC-annexin A5. Mol Imaging. 2014; 13: 1-10.

79. Mukherjee A, Kothari K, Tóth G, Szemenyei E, Sarma HD, Környei J, et al. 99mTc-labeled annexin V fragments: a potential SPECT radiopharmaceutical for imaging cell death. Nucl Med Biol. 2006; 33: 635-43.

80. Tait JF, Smith C, Levashova Z, Patel B, Blankenberg FG, Vanderheyden JL. Improved detection of cell death in vivo with annexin $\mathrm{V}$ radiolabeled by site-specific methods. J Nucl Med. 2006; 47: 1546-53.

81. Yagle KJ, Eary JF, Tait JF, Grierson JR, Link JM, Lewellen B, et al. Evaluation of ${ }^{18 \mathrm{~F}-a n n e x i n} \mathrm{~V}$ as a PET imaging agent in an animal model of apoptosis. J Nucl Med. 2005; 46: 658-66.

82. Murakami Y, Takamatsu H, Taki J, Tatsumi M, Noda A, Ichise R, et al. 18F-labelled annexin V: a PET tracer for apoptosis imaging. Eur J Nucl Med Mol Imaging. 2004; 31: 469-74.

83. Hu S, Kiesewetter DO, Zhu L, Guo N, Gao H, Liu G, et al. Longitudinal PET imaging of doxorubicin-induced cell death with ${ }^{18} \mathrm{~F}$-Annexin V. Mol Imaging Biol. 2012; 14: 762-70.

84. Falborg L, Waehrens LN, Alsner J, Bluhme H, Frøkiaer J, Heegaard CW, et al. Biodistribution of ${ }^{99 \mathrm{~m} T \mathrm{c}-H Y N I C-l a c t a d h e r i n}$ in mice-a potential tracer for visualizing apoptosis in vivo. Scand J Clin Lab Invest. 2012; 70: 209-16.

85. Poulsen RH, Rasmussen JT, Ejlersen JA, Flø C, Falborg L, Heegaard CW, et al. Pharmacokinetics of the phosphatidylserine tracers $99 \mathrm{mTc}$-lactadherin and 99mTc-annexin $\mathrm{V}$ in pigs. EJNMMI Res. 2013; 3: 15.

86. Xiong C, Brewer K, Song S, Zhang R, Lu W, Wen X, et al. Peptide-based imaging agents targeting phosphatidylserine for the detection of apoptosis. J Med Chem. 2011; 54: 1825-35.

87. Song S, Xiong C, Lu W, Ku G, Huang G, Li C. Apoptosis imaging probe predicts early chemotherapy response in preclinical models: A comparative study with ${ }^{18} \mathrm{~F}-\mathrm{FDG}$ PET. J Nucl Med. 2013; 54: 104-10.

88. Marconescu A, Thorpe PE. Coincident exposure of phosphatidylethanolamine and anionic phospholipids on the surface of irradiated cells. Biochim Biophys Acta. 2008; 1778: 2217-24

89. Zhao M, Li Z, Bugenhagen S, 99mTc-labeled duramycin as a novel phosphatidylethanolamine-binding molecular probe. J Nucl Med. 2008; 49: 1345-52.

90. Johnson SE, Li Z, Liu Y, Moulder JE, Zhao M. Whole-body imaging of high-dose ionizing irradiation-induced tissue injuries using $99 \mathrm{mTc}$-duramycin. J Nucl Med. 2013; 54: 1397-403.

91. Zhang Y, Stevenson GD, Barber C, Furenlid LR, Barrett HH, Woolfenden JM, et al. Imaging of rat cerebral ischemia-reperfusion injury using ${ }^{99 \mathrm{~m} T c}$-labeled duramycin. Nucl Med Biol. 2013; 40: 80-8.

92. Zhao M, Li Z. A single-step kit formulation for the ${ }^{99 \mathrm{~m} T c-l a b e l i n g}$ of HYNIC-Duramycin. Nucl Med Biol. 2012; 39: 1006-11.

93. Ohsawa S, Hamada S, Yoshida H, Miura M. Caspase-mediated changes in histone H1 in early apoptosis: prolonged caspase activation in developing olfactory sensory neurons. Cell Death Differ. 2008; 15: 1429-39. 
94. Wang K, Purushotham S, Lee JY, Na MH, Park H, Oh SJ, et al. In vivo imaging of tumor apoptosis using histone H1-targeting peptide. J Control Release. 2010; 148: 283-91.

95. Haberkorn U, Kinscherf R, Krammer PH, Mier M, Eisenhut M. Investigation of a potential scintigraphic marker of apoptosis: radioiodinated Z-Val-Ala-DL-Asp(O-methyl)-fluoromethyl ketone. Nucl Med Biol. 2001; 28: 793-8.

96. Bauer C, Bauder-Wuest U, Mier W, Haberkorn U, Eisenhut M. ${ }^{131}$ I-labeled peptides as caspase substrates for apoptosis imaging. J Nucl Med. 2005; 46: 1066-74.

97. Su H, Chen G, Gangadharmath U, Gomez LF, Liang Q, Mu F, et al. Evaluation of $\left[{ }^{18} \mathrm{~F}\right]-\mathrm{CP} 18$ as a PET imaging tracer for apoptosis. Mol Imaging Biol. 2013; 15 : $739-47$.

98. Xia $\mathrm{CF}$, Chen $\mathrm{G}$, Gangadharmath $\mathrm{U}$, Gomez $\mathrm{LF}$, Liang $\mathrm{O}, \mathrm{Mu} \mathrm{F}$, et al. In vitro and in vivo evaluation of the caspase- 3 substrate-based radiotracer $\left[{ }^{18} \mathrm{~F}\right]-\mathrm{CP} 18$ for PET imaging of apoptosis in tumors. Mol Imaging Biol. 2013; 15: 748-57.

99. Doss M, Kolb HC, Walsh JC, Mocharla V, Fan H, Chaudhary A, et al. Biodistribution and radiation dosimetry of ${ }^{18} \mathrm{~F}-\mathrm{CP}-18$, a potential apoptosis imaging agent, as determined from PET/CT scans in healthy volunteers. J Nucl Med. 2013; 54: 2087-92.

100. Niu G, Chen X. Molecular imaging with activatable reporter systems. Theranostics. 2012; 2: 413-23.

101. Wang F, Wang Z, Hida N, Kiesewetter DO, Ma Y, Yang K, et al. A cyclic HSV1-TK reporter for real-time PET imaging of apoptosis. Proc Natl Acad Sci U S A. 2014; 111: 5165-70.

102. Koulov AV, Stucker KA, Lakshmi C, Robinson JP, Smith BD. Detection of apoptotic cells using a synthetic fluorescent sensor for membrane surfaces that contain phosphatidylserine. Cell Death Differ. 2003; 10: 1357-9.

103. Hanshaw RG, Smith BD. New reagents for phosphatidylserine recognition and detection of apoptosis. Bioorg Med Chem. 2005; 13: 5035-42.

104. Smith BA, Xiao S, Wolter W, Wheeler J, Suckow MA, Smith BD. In vivo targeting of cell death using a synthetic fluorescent molecular probe. Apoptosis. 2011; 16: 722-31.

105. Smith BA, Xie BW, van Beek ER, Que I, Blankevoort V, Xiao S, et al. Multicolor fluorescence imaging of traumatic brain injury in a cryolesion mouse model. ACS Chem Neurosci. 2012; 3: 530-7

106. Wyffels L, Gray BD, Barber C, Moore SK, Woolfenden JM, Pak KY, et al. Synthesis and preliminary evaluation of radiolabeled bis(zinc(II)-dipicolylamine) coordination complexes as cell death imaging agents. Bioorg Med Chem. 2011; 19: 3425-33.

107. Oltmanns D, Zitzmann-Kolbe S, Mueller A, Bauder-Wuest U, Schaefer M, Eder $\mathrm{M}$, et al. $\mathrm{Zn}$ (II)-bis(cyclen) complexes and the imaging of apoptosis/necrosis. Bioconjug Chem. 2011; 22: 2611-24.

108. Liu X, Cheng D, Gray BD, Wang Y, Akalin A, Rusckowski M, et al. Radiolabeled Zn-DPA as a potential infection imaging agent. Nucl. Med. Biol. 2012; 39: 709-14

109. Aloya R, Shirvan A, Grimberg H, Reshef A, Levin G, Kidron D, et al. Molecular imaging of cell death in vivo by a novel small molecule probe. Apoptosis. 2006; 11: 2089-101.

110. Reshef A, Shirvan A, Grimberg H, Levin G, Cohen A, Mayk A, et al. Novel molecular imaging of cell death in experimental cerebral stroke. Brain Res. 2007; 1144: 156-64.

111. Cohen A, Ziv I, Aloya T, Levin G, Kidron D, Grimberg H, et al. Monitoring of chemotherapy-induced cell death in melanoma tumors by N,N'-Didansyl-L-cystine. Tech Cancer Res T. 2007; 6: 221-34.

112. Grimberg H, Levin G, Shirvan A, Cohen A, Reshef A, Ziv I. Monitoring of tumor response to chemotherapy in vivo by a novel small-molecule detector of apoptosis. Apoptosis 2009; 14: 257-67.

113. Reshef A, Shirvan A, Waterhouse RN, Grimberg H, Levin G, Cohen A, et al. Molecular imaging of neurovascular cell death in experimental cerebral stroke by PET. J Nucl Med. 2008; 49: 1520-8.

114. Höglund J, Shirvan A, Antoni G, Gustavsson SÅ, Långström B, Ringheim A, et al. ${ }^{8}$ F-ML-10, a PET tracer for apoptosis: first human study. J Nucl Med. 2011; 52: $720-5$.

115. Shirvan A, Reshef A, Allen A, Fenig E, Stenmetz A, Groshar D, et al. Apoptosis imaging with PET-18F-ML-10 for early assessment of response of brain metastases to radiotherapy. J Nucl Med. 2009; 50(Suppl 2): S453.

116. Allen AM, Ben-Ami M, Reshef A, Steinmetz A, Kundel Y, Inbar E, et al. Assessment of response of brain metastases to radiotherapy by PET imaging of apoptosis with 18F-ML-10. Eur J Nucl Med Mol Imaging. 2012; 39: 1400-8.

117. Bauwens M, de Saint-Hubert M, Cleynhens J, Brams L, Devos E, Mottaghy FM, et al. Radioiodinated phenylalkyl malonic acid derivatives as pH-sensitive SPECT tracers. PLoS One. 2012; 7: 38428.

118. Smith BA, Smith BD. Biomarkers and molecular probes for cell death imaging and targeted therapeutics. Bioconjug Chem. 2012; 23: 1989-2006.

119. Zeng W, Yao M, Townsend D, Kabalka G, Wall J, Miao W. Biological evaluation of dansylhydrazone derivatives for cancer cell apoptosis imaging. J Nucl Med. 2008; 49(Suppl 1): S351.

120. Zeng W, Yao M, Townsend D, Kabalka G, Wall J, Lepuil M, et al. Synthesis and biological evaluation of (E)-5-(dimethylamino)-N'-(4-fluoro-benzylidene)-naphthalene-1-sulfonohydra zide [DFNSH] as an agent for imaging apoptosis. J Nucl Med. 2008; 49(Suppl 1): $\mathrm{S} 294$

121. Zeng W, Yao ML, Townsend D, Kabalka G, Wall J, Le Puil M, et al. Synthesis, biological evaluation and radiochemical labeling of a dansylhydrazone deriv- ative as a potential imaging agent for apoptosis. Bioorg Med Chem Lett. 2008; 18: 3573-7

122. Zeng W, Miao W, Le Puil M, Shi G, Biggerstaff J, Kabalka GW, et al. Design, synthesis, and biological evaluation of 4-(5-dimethylamino-naphthalene-1-sulfon-amido)-3-(4-iodophenyl)butanoic acid as a novel molecular probe for apoptosis imaging. Biochem Biophys Res Commun. 2010; 398: 571-5.

123. Lee D, Long SA, Murray JH, Adams JL, Nuttall ME, Nadeau DP, et al. Potent and selective nonpeptide inhibitors of caspases 3 and 7. J Med Chem. 2001; 44: 2015-26

124. Chu W, Zhang J, Zeng C, Rothfuss J, Tu Z, Chu Y, et al. N-benzylisatin sulfonamide analogues as potent caspase- 3 inhibitors: synthesis, in vitro activity, and molecular modeling studies. J Med Chem. 2005; 48: 7637-47.

125. Kopka K, Faust A, Keul P, Wagner S, Breyholz HJ, Höltke C, et al. 5-pyrrolidinylsulfonyl isatins as a potential tool for the molecular imaging of caspases in apoptosis. J Med Chem. 2006; 49: 6704-15.

126. Zhou D, Chu W, Rothfuss J, Zeng C, Xu J, Jones L, et al. Synthesis, radiolabeling, and in vivo evaluation of an ${ }^{18} \mathrm{~F}$-labeled isatin analog for imaging caspase-3 activation in apoptosis. Bioorg Med Chem Lett. 2006; 16: 5041-6.

127. Barthel H, Cleij MC, Collingridge DR, Hutchinson OC, Osman S, He Q, et al. 3'-deoxy-3'-[ $\left.{ }^{18} \mathrm{~F}\right]$ fluorothymidine as a new marker for monitoring tumor response to antiproliferative therapy in vivo with positron emission tomography. Cancer Res. 2003; 63: 3791-8.

128. Leyton J, Latigo JR, Perumal M, Dhaliwal H, He Q, Aboagye EO. Early detection of tumor response to chemotherapy by 3 '-deoxy-3'-[18F]fluorothymidine positron emission tomography: the effect of cisplatin on a fibrosarcoma tumor model in vivo. Cancer Res. 2005; 65: 4202-10.

129. Kenny L, Coombes RC, Vigushin DM, Al-Nahhas A, Shousha S, Aboagye EO. Imaging early changes in proliferation at 1 week post chemotherapy: a pilot study in breast cancer patients with 3'-deoxy-3'-[18 $\mathrm{F}]$ fluorothymidine positron emission tomography. Eur J Nucl Med Mol Imaging. 2007; 34: 1339-47.

130. Nguyen QD, Smith G, Glaser M, Perumal M, Arstad E, Aboagye EO. Positron emission tomography imaging of drug-induced tumor apoptosis with a caspase-3/7 specific $\left[{ }^{18} \mathrm{~F}\right]$-labeled isatin sulfonamide. Proc Natl Acad Sci U S A. 2009; 106: 16375-80.

131. Glaser M, Goggi J, Smith G, Morrison M, Luthra SK, Robins E, et al. Improved radiosynthesis of the apoptosis marker ${ }^{18} \mathrm{~F}-\mathrm{ICMT} 11$ including biological evaluation. Bioorg Med Chem Lett. 2011; 21: 6945-9.

132. Nguyen QD, Challapalli A, Smith G, Fortt R, Aboagye EO. Imaging apoptosis with positron emission tomography: 'bench to bedside' development of the caspase-3/7 specific radiotracer [18F]ICMT-11. Eur J Cancer. 2012; 48: 432-40.

133. Challapalli A, Kenny LM, Hallett WA, Kozlowski K, Tomasi G, Gudi M, et al. ${ }^{18}$ F-ICMT-11, a caspase-3-specific PET tracer for apoptosis: biodistribution and radiation dosimetry. J Nucl Med. 2013; 54: 1551-6.

134. Ly JD, Grubb DR, Lawen A. The mitochondrial membrane potential (deltapsi(m)) in apoptosis; an update. Apoptosis. 2003; 8: 115-28.

135. Madar I, Ravert HT, Du Y, Hilton J, Volokh L, Dannals RF, et al. Characterization of uptake of the new PET imaging compound $18 \mathrm{~F}$-fluorobenzyl triphenyl phosphonium in dog myocardium. J Nucl Med. 2006; 47: 1359-66.

136. Madar I, Ravert H, Nelkin B, Abro M, Pomper M, Dannals R, et al. Characterization of membrane potential-dependent uptake of the novel PET tracer ${ }^{18}$ F-fluorobenzyl triphenylphosphonium cation. Eur J Nucl Med Mol Imaging. 2007; 34: 2057-65.

137. Madar I, Huang Y, Ravert H, Dalrymple SL, Davidson NE, Isaacs JT, et al. Detection and quantification of the evolution dynamics of apoptosis using the PET voltage sensor ${ }^{18} \mathrm{~F}-$ fluorobenzyl triphenyl phosphonium. J Nucl Med. 2009; 50: 774-80

138. Nguyen OD, Aboagye EO. Imaging the life and death of tumors in living subjects: Preclinical PET imaging of proliferation and apoptosis. Integr Biol. 2010; 2: 483-95.

139. Rodina A, Vilenchik M, Moulick K, Aguirre J, Kim J, Chiang A, et al. Selective compounds define Hsp90 as a major inhibitor of apoptosis in small-cell lung cancer. Nat Chem Biol. 2007;3: 498-507.

140. Banerji U. Heat shock protein 90 as a drug target: some like it hot. Clin Cancer Res. 2009; 15: 9-14.

141. Park D, Don AS, Massamiri T, Karwa A, Warner B, MacDonald J, et al. Noninvasive imaging of cell death using an Hsp90 ligand. J Am Chem Soc. 2011; 133: 2832-5.

142. Kumar S, Richards-Kortum R. Optical molecular imaging agents for cancer diagnostics and therapeutics. Nanomedicine. 2006; 1: 23-30.

143 Achilefu S. The insatiable quest for near-infrared fluorescent probes for molecular imaging. Angew Chem Int Ed. 2010; 49: 9816-8.

144. Li C, Lee CJ, Simeone DM. Identification of human pancreatic cancer stem cells. Methods Mol Biol. 2009; 568: 161-73.

145. Xia Z, Rao J. Biosensing and imaging based on bioluminescence resonance energy transfer. Curr. Opin Biotechnol. 2009; 20: 37-44.

146. Petrovsky A, Schellenberger E, Josephson L, Weissleder R, Bogdanov A Jr. Near-infrared fluorescent imaging of tumor apoptosis. Cancer Res. 2003; 63: 1936-42.

147. Ntziachristos V, Schellenberger EA, Ripoll J, Yessayan D, Graves E, Bogdanov A Jr, et al. Visualization of antitumor treatment by means of fluorescence molecular tomography with an annexin V-Cy5.5 conjugate. Proc Natl Acad Sci U S A. 2004; 101: 12294-9.

148. Smith BA, Akers WJ, Leevy WM, Lampkins AJ, Xiao S, Wolter W, et al. Optical imaging of mammary and prostate tumors in living animals using a 
synthetic near infrared zinc(II)-dipicolylamine probe for anionic cell surfaces. J Am Chem Soc. 2010; 132: 67-9.

149. Smith BA, Gammon ST, Xiao S, Wang W, Chapman S, McDermott R, et al. In vivo optical imaging of acute cell death using a near-infrared fluorescent zinc-dipicolylamine probe. Mol Pharm. 2011; 8: 583-90.

150. Weissleder R, Pittet MJ. Imaging in the era of molecular oncology. Nature. 2008; 452: 580-9.

151. Kobayashi H, Choyke PL. Target-cancer-cell-specific activatable fluorescence imaging probes: rational design and in vivo applications. Acc Chem Res. 2011; 44: 83-90.

152. Elias DR, Thorek DL, Chen AK, Czupryna J, Tsourkas A. In vivo imaging of cancer biomarkers using activatable molecular probes. Cancer Biomark. 2008; 4: 287-305.

153. Huang X, Lee S, Chen X. Design of "smart" probes for optical imaging of apoptosis. Am J Nucl Med Mol Imaging. 2007; 1: 3-17.

154. Bullok K, Piwnica-Worms D. Synthesis and characterization of a small, membrane-permeant, caspase-activatable far-red fluorescent peptide for imaging apoptosis. J Med Chem. 2005; 48: 5404-7.

155. Bullok KE, Maxwell D, Kesarwala AH, Gammon S, Prior JL, Snow M, et al. Biochemical and in vivo characterization of a small, membrane-permeant, caspase-activatable far-red fluorescent peptide for imaging apoptosis. Biochemistry. 2007; 46: 4055-65.

156. Barnett EM, Zhang X, Maxwell D, Chang Q, Piwnica-Worms D. Single-cell imaging of retinal ganglion cell apoptosis with a cell-penetrating, activatable peptide probe in an in vivo glaucoma model. Proc Natl Acad Sci U S A. 2009; 106: 9391-6.

157. Maxwell D, Chang Q, Zhang X, Barnett EM, Piwnica-Worms D. An improved cell-penetrating, caspase-activatable, near-infrared fluorescent peptide for apoptosis imaging. Bioconjug Chem. 2009; 20: 702-9.

158. Lee S, Choi KY, Chung H, Ryu JH, Lee A, Koo H, et al. Real time, high resolution video imaging of apoptosis in single cells with a polymeric nanoprobe. Bioconjug Chem. 2011; 22: 125-31.

159. Zhu L, Huang X, Choi KY, Ma Y, Zhang F, Liu G, et al. Real-time monitoring of caspase cascade activation in living cells. J Control Release. 2012; 163: 55-62.

160. Huang X, Swierczewska M, Choi KY, Zhu L, Bhirde A, Kim K, et al. Multiplex imaging of an intracellular proteolytic cascade by using a broad-spectrum nanoquencher. Angew Chem Int Ed. 2012; 51: 1625-30.

161. Troy T, Jekic-McMullen D, Sambucetti L, Rice B. Quantitative comparison of the sensitivity of detection of fluorescent and bioluminescent reporters in animal models. Mol Imaging. 2004; 3: 9-23.

162. Ponomarev V, Doubrovin M, Serganova I, Vider J, Shavrin A, Beresten T, et al. A novel triple-modality reporter gene for whole-body fluorescent, bioluminescent, and nuclear noninvasive imaging. Eur J Nucl Med Mol Imaging. 2004; 31: 740-51.

163. Kanno A, Yamanaka $Y$, Hirano $H$, Umezawa $Y$, Ozawa T. Cyclic luciferase for real-time sensing of caspase-3 activities in living mammals. Angew Chem Int Ed. 2007; 46: 7595-9.

164. Zhang F, Zhu L, Liu G, Hida N, Lu G, Eden HS, et al. Multimodality imaging of tumor response to doxil. Theranostics. 2011; 1: 302-9.

165. Niu G, Zhu L, Ho DN, Zhang F, Quan Q, Hida N, et al. Longitudinal bioluminescence imaging of the dynamics of Doxorubicin induced apoptosis. Theranostics. 2013; 3: 190-200.

166. Bhaumik S, Gambhir SS. Optical imaging of Renilla luciferase reporter gene expression in living mice. Proc Natl Acad Sci U S A. 2002; 99: 377-82

167. Shah K, Tang Y, Breakefield X, Weissleder R. Real-time imaging of TRAIL-induced apoptosis of glioma tumors in vivo. Oncogene. 2003; 22: 6865-72

168. Angers S, Salahpour A, Joly E, Hilairet S, Chelsky D, Dennis M, et al. Detection of beta 2-adrenergic receptor dimerization in living cells using bioluminescence resonance energy transfer (BRET). Proc Natl Acad Sci U S A. 2000; 97: 3684-9.

169. Blamire AM. The technology of MRI--the next 10 years? Br J Radiol. 2008; 81: 601-17.

170. Caravan P, Ellison JJ, McMurry TJ, Lauffer RB. Gadolinium(III) chelates as MRI contrast agents: structure, dynamics, and applications. Chem Rev. 1999; 99: 2293-352.

171. Lee N, Hyeon T. Designed synthesis of uniformly sized iron oxide nanoparticles for efficient magnetic resonance imaging contrast agents. Chem Soc Rev. 2012; 41: 2575-89.

172. Zhou Z, Lu ZR. Gadolinium-based contrast agents for magnetic resonance cancer imaging. Wiley Interdiscip Rev Nanomed Nanobiotechnol. 2013; 5: $1-18$

173. Xie J, Liu G, Eden HS, Ai H, Chen X. Surface-engineered magnetic nanoparticle platforms for cancer imaging and therapy. Acc Chem Res. 2011; 44: 883-92.

174. Tan H, Yu L, Gao F, Liao W, Wang W, Zeng W. Surface modification: how nanoparticles assemble to molecular imaging probes. J Nanopart Res. 2013; 15: 2100-15.

175. Caravan P. Strategies for increasing the sensitivity of gadolinium based MRI contrast agents. Chem Soc Rev. 2006; 35: 512-23.

176. Hiller $\mathrm{KH}$, Waller C, Nahrendorf M, Bauer WR, Jakob PM. Assessment of cardiovascular apoptosis in the isolated rat heart by magnetic resonance molecular imaging. Mol Imaging. 2006;5: 115-21.

177. van Tilborg GA, Mulder WJ, Deckers N, Storm G, Reutelingsperger CP, Strijkers GJ, et al. Annexin A5-functionalized bimodal lipid-based contrast agents for the detection of apoptosis. Bioconjug Chem. 2006; 17: 741-9.
178. van Tilborg GA, Vucic E, Strijkers GJ, Cormode DP, Mani V, Skajaa T, et al. Annexin A5-functionalized bimodal nanoparticles for MRI and fluorescence imaging of atherosclerotic plaques. Bioconjug Chem. 2011; 21: 1794-803.

179. Krishnan AS, Neves AA, de Backer MM, Hu DE, Davletov B, Kettunen MI, et al. Detection of cell death in tumors by using MR imaging and a gadolinium-based targeted contrast agent. Radiology. 2008; 246: 854-62.

180. Burtea C, Laurent S, Lancelot E, Ballet S, Murariu O, Rousseaux O, et al. Peptidic targeting of phosphatidylserine for the MRI detection of apoptosis in atherosclerotic plaques. Mol Pharm. 2009; 6: 1903-19.

181. Kikuchi K. Design, synthesis and biological application of chemical probes for bio-imaging. Chem Soc Rev. 2010; 39: 2048-53.

182. Mizukami S, Takikawa R, Sugihara F, Hori Y, Tochio H, Wälchli M, et al. Paramagnetic relaxation-based ${ }^{19} \mathrm{~F}$ MRI probe to detect protease activity. J Am Chem Soc. 2008; 130: 794-5.

183. Mizukami S, Takikawa R, Sugihara F, Shirakawa M, Kikuchi K. Dual-function probe to detect protease activity for fluorescence measurement and ${ }^{19} \mathrm{~F}$ MRI. Angew Chem Int Ed. 2009; 48: 3641-3.

184. Yoo B, Pagel MD. A PARACEST MRI contrast agent to detect enzyme activity. J Am Chem Soc. 2006; 128: 14032-3.

185. Reddy LH, Arias JL, Nicolas J, Couvreur P. Magnetic nanoparticles: design and characterization, toxicity and biocompatibility, pharmaceutical and biomedical applications. Chem Rev. 2012; 112: 5818-78.

186. Tassa C, Shaw SY, Weissleder R. Dextran-coated iron oxide nanoparticles: a versatile platform for targeted molecular imaging, molecular diagnostics, and therapy. Acc Chem Res. 2011; 44: 842-52.

187. Schellenberger EA, Bogdanov A, Högemann D, Tait J, Weissleder R, Josephson L. Annexin V-CLIO: a nanoparticle for detecting apoptosis by MRI. Mol Imaing. $2002 ; 1: 102-7$

188. van Tilborg GA, Geelen T, Duimel H, Bomans PH, Frederik PM, Sanders HM, et al. Internalization of annexin A5-functionalized iron oxide particles by apoptotic Jurkat cells. Contrast Media Mol Imaging. 2009; 4: 24-32.

189. Oling F, Santos JS, Govorukhina N, Mazères-Dubut C, Bergsma-Schutter W, Oostergetel G, et al. Structure of membrane-bound annexin A5 trimers: a hybrid cryo-EM - X-ray crystallography study. J Mol Biol. 2000; 304: 561-73.

190. Zhao M, Beauregard DA, Loizou L, Davletov B, Brindle KM. Non-invasive detection of apoptosis using magnetic resonance imaging and a targeted contrast agent. Nat Med. 2001; 7: 1241-4.

191. Radermacher KA, Boutry S, Laurent S, Elst LV, Mahieu I, Bouzin C, et al. Iron oxide particles covered with hexapeptides targeted at phosphatidylserine as MR biomarkers of tumor cell death. Contr Media Mol Imaging. 2010; 5: 258-67.

192. Radermacher KA, Magat J, Bouzin C, Dresselaers T, Himmelreich U, Boutry S, et al. Multimodal assessment of early tumor response to chemotherapy: comparison between diffusion-weighted MRI, ${ }^{1} \mathrm{H}-\mathrm{MR}$ spectroscopy of choline and USPIO particles targeted at cell death. NMR Biomed. 2011; 25: 514-22.

193. Burtea C, Ballet S, Laurent S, Rousseaux O, Dencausse A, Gonzalez W, et al. Development of a magnetic resonance imaging protocol for the characterization of atherosclerotic plaque by using vascular cell adhesion molecule- 1 and apoptosis-targeted ultrasmall superparamagnetic iron oxide derivatives. Arterioscler Thromb Vasc Biol. 2012; 32: e36-348.

194. Willmann JK, van Bruggen N, Dinkelborg LM, Gambhir SS. Molecular imaging in drug development. Nat Rev Drug Discovery. 2008; 7: 591-607.

195. Louie A. Multimodality imaging probes: design and challenges. Chem Rev. 2010; 110: 3146-95.

196. Sapsford KE, Algar WR, Berti L, Gemmill KB, Casey BJ, Oh E, et al. Functionalizing nanoparticles with biological molecules: developing chemistries that facilitate nanotechnology. Chem Rev. 2013; 113: 1904-2074.

197. Xing Y, Zhao J, Conti PS, Chen K. Radiolabeled nanoparticles for multimodality tumor imaging. Theranostics. 2014; 4: 290-306.

198. Lee DE, Koo H, Sun IC, Ryu JH, Kim K, Kwon IC. Multifunctional nanoparticles for multimodal imaging and theragnosis. Chem Soc Rev. 2012; 41: 2656-72.

199. Schellenberger EA, Sosnovik D, Weissleder R, Josephson L. Magneto/optical annexin V, a multimodal protein. Bioconjug Chem. 2004; 15: 1062-7.

200. Sosnovik DE, Schellenberger EA, Nahrendorf M, Novikov MS, Matsui T, Dai $\mathrm{G}$, et al. Magnetic resonance imaging of cardiomyocyte apoptosis with a novel magneto-optical nanoparticle. Magn Reson Med. 2005; 54: 718-24.

201. van Tilborg GA, Mulder WJ, Chin PT, Storm G, Reutelingsperger CP, Nicolay $\mathrm{K}$, et al. Annexin A5-conjugated quantum dots with a paramagnetic lipidic coating for the multimodal detection of apoptotic cells. Bioconjug Chem. 2006; 17: $865-8$

202. van Tilborg GA, Vucic E, Strijkers GJ, Cormode DP, Mani V, Skajaa T, et al. Annexin A5-functionalized bimodal nanoparticles for MRI and fluorescence imaging of atherosclerotic plaques. Bioconjug Chem. 2010; 21: 1794-803.

203. Zhang R, Lu W, Wen X, Huang M, Zhou M, Liang D, et al. Annexin A5-conjugated polymeric micelles for dual SPECT and optical detection of apoptosis. J Nucl Med. 2011; 52: 958-64.

204. Zhang $R$, Huang $M$, Zhou $M$, Wen X, Huang $Q$, Li C. Annexin A5-functionalized nanoparticle for multimodal imaging of cell death. Mol Imaging. 2013; 12: 182-90.

205. Zhang L, Zhou H, Belzile O, Thorpe P, Zhao D. Phosphatidylserine-targeted bimodal liposomal nanoparticles for in vivo imaging of breast cancer in mice. J Control Release. 2014; 183: 114-23

206. Lee H, Akers WJ, Cheney PP, Edwards WB, Liang K, Culver JP, et al. Complementary optical and nuclear imaging of caspase- 3 activity using combined activatable and radio-labeled multimodality molecular probe. J Biomed Opt. 2009; 14: 040507 
207. Blankenberg, FG. In vivo detection of apoptosis. J Nucl Med. 2008; 49(Suppl 2): S81-S95.

208. Reshef A, Shirvan A, Akselrod-Ballin A, Wall A, and Ziv I. Small-molecule biomarkers for clinical PET imaging of apoptosis. J Nucl Med. 2010; 51: 837-40.

209. Niu G, Chen X. Apoptosis imaging: beyond annexin V. J Nucl Med. 2010; 51: 1659-62.

210. Vangestel C, Peeters M, Mees G, Oltenfreiter R, Boersma HH, Elsinga PH, et al. In vivo imaging of apoptosis in oncology: an update. Mol Imaging. 2011; 10: 340-58.

211. Neves AA, Brindle KM. Focus on molecular imaging. J Nucl Med. 2014; 55: $1-4$.

212. Chen $K$, Chen X. Design and development of molecular imaging probes. Curr Top Med Chem. 2010; 10: 1227-36.

213. Skovronsky D. Use of eINDs for evaluation of multiple related PET amyloid plaque imaging agents. J Nucl Med. 2008; 49: 4-8.

214. Chi C, Du Y, Ye J, Kou D, Qiu J, Wang J, et al. Intraoperative imaging-guided cancer surgery: from current fluorescence molecular imaging methods to future multi-modality imaging technology. Theranostics. 2014; 4: 1072-84.

215. Shirvan A. Apoptosis imaging with PET-18F-ML-10 for early assessment of response of brain metastasis to radiotherapy. J Nucl Med. 2009; 50(Suppl 1): S118.

216. Martinez MM, Reif RD, Pappas D. Detection of apoptosis: a review of conventional and novel techniques. Anal Methods. 2010; 2: 996-1004.

217. Jokerst JV, Gambhir SS. Molecular imaging with theranostic nanoparticles. Acc Chem Res. 2011; 44: 1050-60.

218. Lammers T, Aime S, Hennink WE, Storm G, Kiessling F. Theranostic nanomedicine. Acc Chem Res. 2011; 44: 1029-38.

219. Chen X, Gambhir SS, Cheon J. Theranostic nanomedicine. Acc Chem Res. 2011; 44: 841 .

220. Xie J, Jon S. Magnetic nanoparticle-based theranostics. Theranostics. 2012; 2: $122-4$.

221. Muthu MS, Leong DT, Mei L, Feng SS. Nanotheranostics - application and further development of nanomedicine strategies for advanced theranostics. Theranostics. 2014; 4: 660-77.

222. Lee S, Kim K. Protease activity: meeting its theranostic potential. Theranostics. 2012; 2: 125-6.

223. Min Y, Li J, Liu F, Yeow EK, Xing B. Near-infrared light-mediated photoactivation of a platinum antitumor prodrug and simultaneous cellular apoptosis imaging by upconversion-luminescent nanoparticles. Angew Chem Int Ed. 2014; 53: 1012-6. 